\title{
JUVENTUD Y DERECHOS POLÍTICOS. UNA NUEVA NARRATIVA DE DERECHOS HUMANOS EN AMÉRICA LATINA
}

\author{
YOUTH AND POLITICAL RIGHTS. A NEW NARRATIVE OF HUMAN RIGHTS IN \\ LATIN AMERICA
}

\begin{abstract}
Mario Cruz Martínez
Profesor-Investigador de Derechos Humanos Universidad Iberoamericana, Santa Fe México. Consultor nacional e internacional de derechos humanos. Doctor y maestro en Derecho, Universidad de Roma II (Italia). Maestro en Filosofía, Universidad de la Sorbona, París (Francia). Abogado por la Universidad Nacional Autónoma de México. Estancia de investigación en la Comisión Interamericana de Derechos Humanos, Washington DC. Email: mario.cruz@ibero.mx
\end{abstract}

Convidado

RESUMEN: El ensayo analiza la perspectiva de derechos humanos de los derechos políticos de los jóvenes en América Latina concibiendo tres ámbitos esenciales. En primer lugar, la complejidad de la construcción del sujeto joven y el desarrollo de los estudios juveniles desde las teorías sociales; posteriormente, se estudia las libertades políticas de los jóvenes en contextos de violencia y su importancia en la generación de agendas sociales y de bienestar social, y finalmente, se hace una reflexión sobre la contribución del Sistema Interamericano a la protección y defensa del sujeto joven.

Palabras clave: Derechos Humanos; Derechos Políticos; Jóvenes; Movimiento Sociales

ABSTRACT:Youth and Political Rights: A new narrative of Human Rights in Latin America: This document analyses the human rights' prospective of political rights of young people in three aspects: a) The complexity of social building of young people and the development of juvenile literature from social theories; b) An analysis of the political liberties of young people in violent contexts and its importance in the creation of social agendas and social welfare. c) It makes a reflection on the Inter-American Human Rights System and its protection, furthermore, the inbuilt defence mechanisms that exists for young people.

Keywords: Human Rights; Political Rights; Young People; Social Movements.

SUMARIO: I. Introducción; II. Nuevas narrativas juveniles en América;a. Indignación, violencia y juventud; b. Juventudes y los discursos de la perplejidad en América Latina; III. Los jóvenes en el mundo; a. Derechos políticos, derechos humanos y nuevas narrativas sociales; b. Derechos políticos y juventud; c. Libertades políticas de los jóvenes; IV. El Sistema Interamericano de la Juventud; a. Los derechos políticos desde el sistema interamericano; b. La libertad de expresión juvenil; c. Derecho a la reunión de los jóvenes; d. Manifestaciones sociales y nuevas emociones democráticas de la juventud; e. El derecho de reunión y su contenido; f. Juventud y criminalización de la protesta social; V. Reflexiones finales; VI. Bibliografía mínima; a. Literatura; b. Instrumentos Internacionales y Jurisprudencia Interamericana. 


\section{INTRODUCCIÓN}

Los jóvenes y sus derechos presentan una de las más importantes geografías en los espacios públicos en América Latina ${ }^{1}$.El Informe Juventud 2017 de la OCDE ha señalado: "Nunca antes tuvo Latinoamérica tantos jóvenes. Uno de cada cuatro latinoamericanos tiene entre 15 y 29 años, sumando un total 163 millones de personas" ${ }^{2}$.Sin embargo, los cambios en la geografía política y social que han sacudido la región en los últimos años, han empujado múltiples discusiones que han visibilizado muchas de las demandas juveniles, y han evidenciado una cuestión, los modelos legales, las leyes han invisibilizado las exigencias juveniles, al no existir una regulación efectiva de sus derechos, y en otros caso, los modelos regulatorios han servido más bien, como límites a una amplia y robusta agenda social política de las juventudes. Las razones por las cuales, los jóvenes han sido relegados, son amplias, pero sin duda, un aspecto fundamental es la ambigüedad de su presencia: "La invisibilidad que hasta hace poco tenía el mundo juvenil para el conocimiento científico se refleja en que una de las principales discusiones que aún existen entre los especialistas alude a sus límites de inicio y fin. En otros términos, su existencia social se ha abordado desde su periodización, dado que representaría un momento pasajero que expira con el tiempo" (MEDINA CARRASCO, 2000, p. 79).

El ensayo que a continuación se presenta, busca identificar una nueva línea de reflexión sobre la juventud a través de la consideración de sus libertades políticas en una perspectiva de derechos humanos. Esto permitirá identificarlos estándares de los derechos políticos para su efectiva protección y tutela. De tal suerte, se considerará una referencia obligada en el ámbito latinoamericano, que es el sistema interamericano de derechos humanos.Dicha perspectiva no es nueva, sino sigue esfuerzos importantes que se han desarrollado para la construcción de sujetos especiales, tales como "interés superior de la infancia"; "derechos colectivos"; "propiedad colectiva de pueblos originarios". Asimismo, múltiples reivindicaciones que se han dado en los últimos años en el continente americano, está fraseados por los debates juveniles sobre empleo, educación, pero también sobre temas de frontera, como el debate sobre el matrimonio entre personas del mismo sexo, perspectiva de género, interrupción legal del embarazo, por mencionar algunas cuestiones.

Una cuestión que se ha advertido en la región latinoamericana, es la escasa credibilidad que han tenido los modelos institucionales de derechos humanos. Sin embargo, la propuesta que aquí se presenta, busca plantear una luz de credibilidad en los modelos de derechos fundamentales, y de su tutela efectiva. Cuestiones como libertad de expresión, manifestaciones juveniles, inconformidad y denuncia, reclamos de periodistas y defensores de derechos humanos, han sido parte de la amplia narrativa que ha desarrollado el sistema regional de derechos humanos. Incluso, en algunos casos, la falta de asertividad institucional o negligencia política, ha sido superada por los ejes que ha ido menuzando el modelo de derechos humanos. En una nuez. Los derechos de los jóvenes latinoamericanos, tienen en el modelo regional de derechos humanos, una importante caja de herramientas para su efectiva protección y la reivindicación en los sistemas democráticos.

El descobijo a la juventud latinoamericana no es exclusiva de la región latinoamericana. Las tensiones económicas y políticas han propiciado nuevos escenarios que han dejado desvalidos a millones de personas. Así, es claro que los problemas que han afectado a la juventud

\footnotetext{
${ }^{1}$ En este ensayo no se analizará la discusión sobre el rango de edad de los jóvenes. Se sigue las consideraciones hechas en CRUZ MARTÍNEZ, Mario (2018), Los derechos humanos de los jóvenes (De la vulnerabilidad a la imaginación de los derechos), Tirant Lo Blanch, México, pp. 59-62, donde se analiza el amplio debate del rango de edad para cifrar el sujeto joven. De acuerdo al análisis, en donde se advierte la importante contribución de la Organización de las Naciones Unidas y otros informes de agencias internacionales, la edad juvenil se establece entre los 15-29 años.

2 OCDE/CEPAL/CAF (2016), Perspectivas económicas de América Latina 2017: Juventud, competencias y emprendimiento, OECD Publishing, Paris, p. 15.
}

Revista de Direito Brasileira | São Paulo, SP | v. 19 | n. 8 | p. 250 - 275 |Jan./Abr. 2018 
son estructurales y han nacido bajo el cobijo de amplios procesos de desigualdad y discriminación. Los datos son elocuentes: "En el marco de la reciente crisis económica, el grupo poblacional de los jóvenes se ha visto afectado en mayor medida por el desempleo, que los grupos de adultos. La tasa global de desempleo juvenil pasó de $12.6 \%$ en 2010 a $13.1 \%$ en 2013, lo que representa al menos 74.5 millones de 15 a 24 años desempleados para ese último año" (ÁVALOS GONZÁLEZ, 2015, p.473).Por otra parte, Cécile Van de Velde traza un itinerario crítico de la juventud europea en su obra Devenir adulte ${ }^{3}$. Los entuertos juveniles son de todos y para todos.

Las políticas y medidas de protección se fueron diseñando en espacios donde no se consideraban sus expectativas, o bien considerando a la juventud como un problema social ${ }^{4}$. En esta perspectiva, es importante señalar una importante perspectiva jurídica en la región: Los modelos constitucionales de América Latina han sido más bien ortodoxosen la identificación y protección de nuevas narrativas sociales como los jóvenes. Dentro de este marco de complejidad, es necesario plantear una línea temática donde los jóvenes y sus expectativas sean tutelados por el marco legal; es decir, se requiere identificar una serie de principios que tutelen sus reclamos políticos y advertir, desde el lenguaje de los derechos, posibilidades que potencien las reivindicaciones juveniles dentro de los espacios democráticos.

En los últimos años, la agenda juvenil ha privilegiado cuestiones vinculadas a los amplios procesos de desigualdad, a los que han sido expuestos, y por ello, temas como empleo juvenil, salud productiva, por mencionar algunos, han sido temas obligados de proyectos sociales y políticas públicas generales y sectoriales en la región latinoamericana. Asimismo, un consenso en el ámbito de las ciencia sociales, y que será determinante en el ámbito de los derechos humanos, es la consideración de la juventud como sujeto social. En este marco de análisis, y que privilegia este ensayo, una veta de análisis obligada es el estudio de las libertades políticas de los jóvenes, ya que el ejercicio de sus derechos políticos han forjado nuevas expectativas a los paradigmas políticos, y han evidenciado una particularidad de la mirada juvenil: "La política no es un sistema rígido de normas para los jóvenes, es más bien una red variable de creencias, un bricolaje de formas y estilos de vida, estrechamente vinculada a la cultura" (REGUILLO, 2000, p. 35).

Asimismo, uno de los aspectos que se debe advertir en la agenda juvenil contemporánea, es la robusta bibliografía y metodologías diversas que se han ido desarrollando para identificar muchos de los aspectos y matices de las necesidades y expectativas de los jóvenes en América Latina. Desde la filosofía, antropología, etnología, por mencionar algunas disciplinas ${ }^{5}$, se ha articulado una importante masa crítica, que ha estudiado los fenómenos juveniles y que ha logrado iluminar áreas de análisis para la solución de los entuertos juveniles. Desde los aspectos sociales, y democráticos, donde asoman su perfil los derechos políticos, hasta cuestiones de

\footnotetext{
${ }^{3}$ VAN DE VELDE, Cécile, Devenir adulte (Sociologiecomparée de la jeunesse en Europe) (2008), Francia, PUF, $278 \mathrm{p}$.

4 "Las iniciativas estatales sociales dirigidas al mundo joven han tendido a ser parciales, funcionales y tautológicamente ciegas dad que responden a una visión poco diferenciada de la diversidad juvenil y porque preferentemente se basan en las imágenes que el mundo adulto ha construido de los jóvenes", MEDINA CARRASCO, Gabriel, "La ida se vive en todos lados. La apropiación juvenil de los espacios institucionales", en Aproximaciones a la diversidad juvenil, El Colegio de México, México, 2000, p. 100.

${ }^{5}$ Precisamente la rica literatura social ha identificado las características y matices de las juventudes, para evidenciar a la juventud como un nuevo sujeto social. Por ejemplo, "en el estudio antropológico de las diferentes realidades 'parciales' que configuran la trama urbana, las bandas juveniles han constituido uno de los puntos de mira favoritos: del trabajo clásico de Whyte (1972) sobre los streetcornerboys de Boston a la monografía de Monod (1976) sobre los barjotsde París. Sin embargo, el uso casi exclusivo de la observación participante no siempre ha sido el mejor método para abordar el contexto de relaciones estructurales en que las bandas juveniles se sitúan, ni ha permitido explicitar la dinámica histórica que ha precedido la emergencia de la juventud como nuevo sujeto social", FEIXA PÁMPOLS, Carles, "Los espacios y los tiempos de las culturas juveniles", en Aproximaciones a la diversidad juvenil, Colegio de México, México, 2000, p. 45.
}

Revista de Direito Brasileira | São Paulo, SP | v. 19 | n. 8 | p. 250 - 275 |Jan./Abr. 2018 
justicia social, como empleo juvenil, justicia, salud reproductiva y sexual, o bien los grandes desafíos que plantean los derechos vinculados al acceso a la información pública, se advierten propuestas que han ido nutriendo una importante agenda juvenil del siglo XXI. Como ha señalado Gabriel Medina: "Una propuesta de trabajos sobre el mundo joven latinoamericano representa un pequeño pero significativo paso en la tarea científica de construir saber sobre las realidades sociales de fin de siglo. En lo principal, implica asumir que los jóvenes, en tanto sujeto social e histórico, siguen siendo una gran interrogante para las ciencias sociales" (MEDINA CARRASCO, 2000, p. 10).En esta rica veta de análisis, la perspectiva de los derechos humanos se presenta como una importante propuesta para la tutela efectiva de las exigencias juveniles. Dicho de otra manera, desde la óptica, en los últimos años, se ha desarrollado una importante bibliografía en las teorías de los derechos fundamentales, y se han presentado conceptos tales como, "grupos en estado de vulnerabilidad", "igualdad", "no discriminación", que han conformado una caja de herramientas importante, para la tutela de actores sociales que han sido históricamente marginados.

El siguiente ensayo busca cubrir esencialmente tres niveles en el ámbito de los valores y derechos políticos de las juventudes. Por una parte, identificar el problema delasreivindicaciones políticas de las juventudes y su consideración en los modelos políticos y culturales para orientarlos al amplio continente de los derechos políticos. En esta perspectiva de busca identificar una rica literatura sobre la visibilización de las necesidades juveniles, en espacios adultocéntricos que han dejado de lado muchas de estos ricos modelos y que gradualmente han sido reivindicados en el ejercicio de los derechos políticos de la juventud. En segundo lugar, se buscará señalar cómo la cultura política de los jóvenes está siendo el punto de partida para delinear muchos de los vértices de los paradigmas políticos del siglo XXI y cómo el ejercicio de los derechos políticos de la juventud ha empujado diversas agendas sociales que van desde lo estrictamente político, como en los recientes acontecimientos políticos en Nicaragua, hasta llegar a agendas de seguridad nacional como el movimiento juvenil NeverAgain en Estados Unidos de Norteamérica, en donde después de varios asesinatos de jóvenes a manos de estudiantes, los jóvenes norteamericanos han iniciado un importante movimiento social que ha buscado prohibir el uso de armas. Finalmente, se hará un estudio jurídico de las características de algunos derechos políticos de los jóvenes y su relación con institutos políticos y sociales, como la participación política juvenil, derecho a la manifestación, por mencionar algunas formas del ejercicio de las libertades ciudadanas.

\section{NUEVAS NARRATIVAS JUVENILES EN AMÉRICA}

\section{a. Indignación, violencia y juventud}

Una de las principales formas de análisis de la juventud en América Latina ha sido desde la talanquera de sus expectativas políticas. Los conceptos que han delineado la geografía juvenil desde nuevos valores políticos y sociales, han oscilado desde el desencanto político, hasta la apatía política. Incluso, desde nuevas ópticas de análisis, "en relación con los jóvenes, interesa destacar cuatro grandes áreas que atañen a la biopolítica': la dimensión racial vinculada a la pobreza; el consumo; la moral pública y, por último, la dimensión de género" (REGUILLO, 2012, p. 60) En esta perspectiva, se han realizado esfuerzos importantes para el estudio de la realidad juvenil, y especialmente desde la visión política ${ }^{7}$ y social. Asimismo, en los últimos

\footnotetext{
${ }^{6}$ Según Foucault, la biopolítica tiene como objetivo, "el sometimiento del cuerpo a una disciplina que lleva a la optimización de sus capacidades y al incremento de su utilidad" (citado por REGUILLO, 2012, p. 60).

${ }^{7}$ Por ejemplo, el Grupo de Trabajo CLACSO "Juventud y nuevas prácticas políticas en América Latina" ha planteado nuevas metodologías "en torno a la ciudadanía de jóvenes en América Latina y sus nuevas formas de hacer política desde lo juvenil, profundizando en las maneras particulares como los y las jóvenes se vinculan a la Revista de Direito Brasileira | São Paulo, SP | v. 19 | n. 8 | p. 250 - 275 |Jan./Abr. 2018
} 
años, se han identificado diversos acontecimientos que brindan una nueva perspectiva para el análisis que nos ocupa. Cito tres casosrecientes de la región americana, en donde la juventud ha sido protagonista u objeto de análisis, y que plantea diversas problemáticas que son guiadas por la juventud, como núcleo central de la discusión.

- El caso Ayotzinapa en México ${ }^{8}$. La desaparición de 43 jóvenes en Iguala, Guerrero. En 2014, 43 jóvenes fueron secuestrados en Iguala, por agentes del Estado, y abrieron una herida en México y en América Latina. La primera respuesta a los padres de las víctimas fue la victimización y posteriormente, el gobierno federal asumió el control de las investigaciones. La forma en cómo fueron desaparecidos los jóvenes fue un parteaguas en México y comenzó un movimiento social, en donde se ha denunciado la desaparición forzada de los jóvenes y especialmente, se ha advertido la impunidad y corrupción de actores institucionales, y la falta de aseguramiento por parte del Estado, de la seguridad jurídica necesaria para poder asegurar el acceso a la justicia de los jóvenes.

- El movimiento de indignación en Nicaragua en 2018. En la primera parte de 2018, Nicaragua ha mostrado al mundo entero, la indignación de los jóvenes por la cerrazón política de Daniel Ortega y cómo la búsqueda de la emancipación política del país centroamericano, ha sido empujado desde las movilizaciones de nicaragüenses, en donde los jóvenes han sido determinantes en la rebelión ciudadana.Por ello, la Comisión Interamericana se pronunció sobre la obligación del Estado nicaragüense para "respetar y garantizar el goce pleno del derecho a la protesta, a la libertad de expresión, a la reunión pacífica y a la participación política de la población"?

-El NeverAgain. En los últimos años, uno de los debates más sensibles en Norteamérica, ha sido la posesión de armas. Después de una serie de tragedias en diferentes escuelas de Estados Unidos, varios jóvenes han logrado articular reclamos objetivos sobre la política del gobierno norteamericano sobre seguridad nacional y la tenencia legítima de armas ${ }^{10}$.

De los tres ejemplos citados, con juventudes en contextos diversos, se advierte cómo el ejercicio de libertades políticas, han logrado plantear una agenda social que cada vez más, evidencia el agotamiento de esquemas políticos tradicionales y que en el ámbito de la libertad de expresión, la manifestación y la inconformidad, se advierte una nueva forma de entender los derechos políticos, en los modelos democráticos. En la época contemporánea, los derechos políticos funcionan en los nuevos tiempos sociales y políticos, como una herramienta fundamental de las democracias contemporáneas y de la creación de nuevos espacios públicos que están siendo empujados por la inconformidad social de la región. En esta nueva forma de entender las expectativas ciudadanas, se plantea en este ensayo, el filón de los derechos humanos

construcción del orden político, para identificar y fortalecer aquellos sentidos, prácticas y discursos más inclusivos, democráticos y participativos", Alvarado, Sara Victoria, y Vommaro, Pablo A., "Presentación", en Jóvenes, cultura y política en América Latina: algunos trayectos de sus relaciones, experiencias y lecturas (1960-2000), CLACSO, pp. 7-8.

${ }^{8}$ Un análisis del Caso Ayotzinapa y su impacto político en México puede ser consultado en: CRUZ MARTÍNEZ, Mario (2017), "El nuevo rostro de la ciudadanía en México frente al Estado de Derecho: los jóvenes y Ayotzinapa", en Perspectivas de los desafíos del Estado de Derecho en el México del Siglo XXI, México, Tirant Lo Blanch, pp. 117-156.

${ }^{9}$ Comisión Interamericana de Derechos Humanos, Observaciones preliminares de la visita de trabajo de la CIDH a Nicaragua, 21 de mayo de 2018 (Disponible en http://www.oas.org/es/cidh/prensa/comunicados/2018/113.asp)

${ }^{10}$ Es emblemático el reclamo de los jóvenes estadounidenses frente a la Cámara de Representantes, reclamando una regulación a la tenencia de armas, que prohiba la posesión a jóvenes. Véase la crónica de WITT, Emily, Urgency and frustration: The Never Again Movement gathers momentum, The New Yorker, 23 de febrero de 2018. (Disponible en: https://www.newyorker.com/news/news-desk/urgency-and-frustration-the-never-again-movement-gathersmomentum). 
para considerar la tutela y protección de derechos como la manifestación pública o la libertad de expresión.

\section{b. Juventudes y los discursos de la perplejidad en América Latina}

Una de las características que explican el perfil de las sociedades latinoamericanas en los últimos años, es la búsqueda de procesos de democratización y del aumento de estándares de bienestar social. Los resultados han sido categóricos. Los robustos modelos regulatorios no han bastado para inhibir el alza de los procesos de desigualdad y mantenimiento de procesos de discriminación estructural. Incluso, una de las más importantes paradojas de América Latina, es la existencia de un buen número de leyes que no corresponden con el desarrollo social ${ }^{11}$. Como ha señalado la CEPAL en su último informe, la desigualdad sigue afectando el bienestar y desarrollo humano: "La desigualdad implica un enorme desaprovechamiento de talentos y capacidades humanas. Además, afecta y corroe la legitimidad política, la deliberación democrática y la convivencia pacífica, exacerbando la violencia y la violación de los derechos"12. Las experiencias en la región han sido relativamente parecidas, con particularidades obvias, que han evidenciado agotamientos de modelos políticos sociales y económicos, que han abierto nuevas vertientes de análisis. Dentro de la rica teoría social sobre los jóvenes se ha señalado "una panorámica de las juventudes como subjetividades generacionales que han iniciado un asalto a la escena política, social y cultural en los distintos países de América Latina, re-politizando espacios naturalizados por las conceptualizaciones de la teoría política e interpelando las matrices canónicas de cierto orden del saber que prevalece en la academia, instalando así un impase político institucional que impone abordarse desde una perspectiva de frontera, en la que las visiones disciplinarias entren en diálogo con otros saberes y, de esta forma, arriesguen otras epistemes" (NATERAS DOMÍNGUEZ, 2015, p. 18)

La democracia en América Latina en los últimos años ha sido puesta en jaque por las juventudes, al evidenciar fallas y falencias sociales y económicas. De acuerdo a datos del PNUD, de los más de 600 millones de personas que viven en América Latina y el Caribe, aproximadamente el $26 \%$ son jóvenes de entre 15 y 29 años. Dicho porcentajees el más alto de población joven en la historia reciente del continente ${ }^{13}$. Precisamente los diversos intereses juveniles, y la múltiples formas de apropiarse de los valores políticos son empujados por los nuevos espacios políticos y por procesos de desgaste de las formas tradicionales de los espacios públicos. Como se ha señalado, "las distintas formas de ser y de vivir la juventud tienen en común que configuran mapas sociales y simbólicos que varían de acuerdo con los modos de apropiación cultural, de control social, de trayectorias laborales y educativas, de vivencias de la realidad sexo-genérica y de la creación de identidades" (BACA TAVIRAet al, 2018, p. 11).

En este panorama de desencanto ciudadano, uno de los desafíos de los regímenes latinoamericanos es incentivar y tutelar la participación política de los jóvenes. Desde el modelo de los derechos humanos, se advierte la relación intrínseca entre identidad y participación

\footnotetext{
${ }^{11} \mathrm{La}$ Comisión Interamericana ha señalado sobre México un rasgo que podría ser aplicable a la región latinoamericana: "En la actualidad, el reto del Estado mexicano es cerrar la brecha existente entre su marco normativo y su apoyo irrestricto a los derechos humanos con la realidad que experimentan un gran número de habitantes cuando buscan una justicia pronta y efectiva. Por lo tanto, el gran desafío del Estado radica en romper el ciclo de impunidad imperante a fin de lograr una efectiva prevención, investigación, procesamiento y sanción de los responsables de violaciones de derechos humanos", Comisión Interamericana de Derechos Humanos, Situación de Derechos Humanos en México, 31 de diciembre de 2015, párafo 13.Disponible en: http://www.oas.org/es/cidh/informes/pdfs/mexico2016-es.pdf

${ }^{12}$ Comisión Económica para América Latina y el Caribe, La ineficiencia de la desigualdad 2018, Disponible en: https://repositorio.cepal.org/bitstream/handle/11362/43442/6/S1800059_es.pdf, p. 15.

${ }^{13}$ Programa de Naciones Unidas para el Desarrollo- PNUD, "Prólogo", en Explorando la Dinámica de la Participación Política Juvenil en la Gobernabilidad Local en América Latina, julio de 2013, pág.15.
} 
política. La célebre Carta Democrática Interamericana consagra el derecho a la participación como un derecho y un deber: "La participación de la ciudadanía en las decisiones relativas a su propio desarrollo es un derecho y una responsabilidad. Es también una condición necesaria para el pleno y efectivo ejercicio de la democracia. Promover y fomentar diversas formas de participación fortalece la democracia ${ }^{14 "}$. Paradójicamente, a pesar de que exista una apatía clara por la participación política, los jóvenes en América Latina han logrado incentivar los resortes de los modelos democráticos a través de la libertad de expresión y de manifestaciones dirigidas a la crítica del poder.Por ello, resulta imprescindible el establecimiento un nuevo paradigma de participación política desde una visión de derechos de los jóvenes que los reconozca como titulares efectivos de derechos y como agentes sociales de desarrollo. En este sentido, una visión de derechos de la juventud incorpora sus amplias expectativas dentro de un marco legal, que permite un desarrollo integral de la juventud: "El enfoque de derechos abandona el énfasis estigmatizante y reduccionista de la juventud como problema. La integración del paradigma que la señala como actor estratégico con el paradigma de juventud ciudadana, permite reconocer su valor como sector flexible y abierto a los cambios, expresión clave de la sociedad y la cultura global, con capacidades y derechos para intervenir protagónicamente en su presente, construir democrática y participativamente su calidad de vida y aportar al desarrollo colectivo" ${ }^{15}$.

La perspectiva de humanos de los jóvenes resulta una efectiva postura política y jurídica para evidenciar las necesidades y expectativas de los jóvenes. Dicho enfoque de derechos humanos pueden identificar "una taxonomía básica de los estándares de derechos humanos de la juventud, a la luz del modelo internacional de los derechos humanos" (CRUZ MARTíNEZ, 2018, p. 294).Así, al observar la geografía de América Latina se puede advertir las inconformidades de las juventudes.En este sentido, se posiciona la participación de los jóvenes en la vida pública y se advierte una ciudadanía activa para lo cual se deben "impulsar procesos de aprendizaje, tanto formal como informal, que les permitan adquirir las capacidades y competencias necesarias para poder participar eficazmente en una sociedad cada vez más compleja y plural" ${ }^{16}$. En materia de participación política, los modelos de derechos humanos han buscado establecer medidas de protección y sobre todo, se ha buscado trazar las nuevas formas de garantizar la complejidad de los derechos políticos de la juventud, en cuestiones tales como la libertad de expresión y la manifestación, en donde la movilización social adquiere un rango preponderante de crítica a los paradigmas políticos.

Uno de los aspectos que se evidencian en el ámbito político de la cultura política de los jóvenes es el concepto de autoridad. Justo, una de las más importantes revoluciones en el ámbito de los modelos políticos es el nuevo concepto de autoridad. Es decir, la evolución gradual de las ideas políticas ha posicionado la nueva forma de análisis de la autoridad. Dos movimientos descuellan en el análisis. El movimiento estudiantil chileno de 2011 y el Movimiento \#YoSoy132 de la Universidad Iberoamericana en la Ciudad de México. El primero posicionó una debate en el país sudamericano sobre la educación púbica, y el movimiento mexicano situó de forma determinante la presencia de los reclamos juveniles en el debate electoral en México de la presidencia en 2012.

Se advierte pues, la importancia de la participación política en las nuevas emociones democráticas de la región latinoamericana. La Oficina de Naciones Unidas para el Apoyo para la Consolidación de la Paz ha señalado los ejes de la participación juvenil: "1.Promover la

\footnotetext{
${ }^{14}$ Carta Democrática Interamericana. Organización de los Estados Americanos. Artículo 6

${ }^{15}$ Krauskopf, Dina (2000). Dimensiones críticas en la participación social de las juventudes. En La participación social y política de los jóvenes en el horizonte del nuevo siglo. Coord. Sergio Balardini. Primera edición. Buenos Aires: CLACSO, Pág. 123

${ }^{16}$ Instituto de la Juventud (2002). La construcción de una ciudadanía activa entre los jóvenes. Primera edición, Madrid. Pág. 20
} 
participación de los jóvenes como condición indispensable para el éxito de la consolidación de la paz.1.1 Dar prioridad a la participación regular, sistemática y significativa de los jóvenes como condición indispensable para la sostenibilidad, la inclusión y el éxito de las actividades de consolidación de la paz. Esto es de particular importancia en aquellos lugares en los que los jóvenes constituyen la mayoría de la población" ${ }^{17}$. Dicha participación política de los jóvenes ha venido a enriquecer desde diversos ángulos, la vida política de América Latina. Desde los sectores urbanos hasta los rurales, la participación juvenil ha adquirido matices que han nutrido las agendas democráticas de la época contemporánea ${ }^{18}$.

De lo anterior, se advierte que la participación juvenil impacta la creación de nuevos modelos legales y de una nueva perspectiva de los derechos humanos.Es por eso que como afirma el informe del Programa de Naciones Unidas para el Desarrollo PNUD titulado "Mejorando la Participación Política de la Juventud a lo largo del Ciclo Electoral. Guía de Buenas Prácticas" la reforma del marco legal constituye un desafío, ya que se requiere un modelo de fácil acceso para los jóvenes y esto es crucial para permitir la participación política de la juventud. En muchos países, las leyes estipulan que la edad requerida para presentarse a elecciones parlamentarias es de al menos 25 años, lo cual crea una brecha entre la edad de mayoría legal y/o la edad de votación, por un lado, y la edad de elegibilidad en la cual una persona puede presentarse a cargos electivos.

\section{LOS JÓVENES EN EL MUNDO}

En los últimos años se ha generado información importante sobre la presencia de los jóvenes en el mundo y su importancia en la geografía económica y social. Como se ha visto, la complejidad de su estudio es la emergencia de los jóvenes ene 1 siglo XX. Algunos autores han señalado la dispersión de la literatura juvenil, y que "en varios casos el objeto principal de estudio no lo constituyen los jóvenes, sino que son enfoques centrados, por ejemplo, en el aparato escolar, en las comunidades eclesiales de base, en las maquiladoras, en los sindicatos, cuyos autores están más interesados en los modos de funcionamiento de instituciones y espacios que en la culturas juveniles" (REGUILLO, 2000, p. 31).Desde 1985, la Organización de las Naciones Unidas planteó la importancia de los jóvenes en el orbe, y señaló uno de los temas que van a estar en la discusión: "Es importante observar que una gran mayoría de los jóvenes viven en países en desarrollo. Según las estimaciones para el año 2000, el $85 \%$ del total de 900 millones de jóvenes vivían en regiones en desarrollo. Según las estimaciones para el año 2000, el $85 \%$ del total de 900 millones de jóvenes vivían en regiones en desarrollo" ${ }^{19}$. Así, se fueron diseñando nuevas propuestas para ir generando soluciones a los problemas y el bienestar de la juventud. La misma ONU ha planteado la geografía contemporánea de las agendas juveniles: "En la actualidad, se pueden determinar tres grandes grupos de cuestiones con los que los jóvenes crecen y se convierten en miembros de sus sociedades. (...) Los tres grupos son los siguientes: a) la juventud

\footnotetext{
${ }^{17}$ Oficina de Apoyo para la Consolidación de la Paz. Principios Rectores sobre la Participación de los Jóvenes en la Consolidación de la Paz. Principio 1.40 Disponible en http://www.un.org/es/peacebuilding/pbso/pdf/guidingprinciples_sp.pdf consultado (Consultado el 9 de septiembre de 2016).

${ }^{18}$ Además, otro aspecto que debe mencionarse sobre la participación política juvenil, es el "desarrollo de las capacidades requeridas para que candidatos jóvenes puedan interactuar con menos disparidades de recursos y de experiencia. Para ello es importante mantener abiertos canales de participación e incidencia permanentes a nivel comunitario, pues ese suele ser un nivel privilegiado para la formación inicial de capacidades de liderazgo político y social", Comisión Económica para América Latina y el Caribe (CEPAL). Juventud: realidades y retos para un desarrollo con igualdad. Santiago. 2015. pág. 252

${ }^{19}$ Organización de las Naciones Unidas, Aplicación del Programa de Acción Mundial para los Jóvenes hasta el año 2000 y años subsiguientes (Informe del Secretario General), p. 2.
}

Revista de Direito Brasileira | São Paulo, SP | v. 19 | n. 8 | p. 250 - 275 |Jan./Abr. 2018 
en la economía mundial, que comprende cuestiones como el hambre y la pobreza, la educación, el empleo, la globalización y las tecnologías de la información y las comunicaciones; b) la juventud en la sociedad civil, relacionado con los problemas del medio ambiente, el ocio, la participación y las relaciones intergeneracionales; y c) los jóvenes en situación de riesgo, que comprende las áreas prioritarias de la salud, la drogadicción, la delincuencia, los conflictos y el VIH/SIDA" ${ }^{20}$. De los ejes planteados por la ONU se atisban necesidades que van surgiendo por reclamos particulares de una juventud que va ejerciendo sus libertades y reclamando al Estado cumplimiento de obligaciones específicas. Como ha señalado Rossana Reguillo sobre el sujeto juvenil, "los contornos imprecisos del sujeto y sus prácticas han colocado al centro de los análisis la vida cotidiana no necesariamente como tema, sino como lugar metodológico desde el cual interrogar a la realidad" (REGUILLO, 2000, p. 32).

Históricamente, la apertura a las necesidades y expectativas de los jóvenes, cuando cuestionan el modelo democrático, ha sido lenta, y por ello, han surgido otras alternativas que han logrado visibilizar los entuertos juveniles. Solo los acontecimientos de los últimos años, han logrado ilustrar la contribución de los jóvenes en la vida pública y política, que han sido reclamos comunes en el mundo entero.Así, se puede identificar una serie de ejes temáticos sobre la juventud que se han materializado en informes y algunos documentos. Este sentido, se puede señalar diversos pronunciamientos. Por ejemplo, la Asamblea General de Naciones Unidas aprobó la Resolución 58/133, en el año 2003, sobre Políticas y programas relativos a la juventud, donde reconoció que "la participación de los jóvenes representa un recurso importante y una condición indispensable para alcanzar el crecimiento económico sostenible y el desarrollo social"21 $^{21}$ Esta resolución está enmarcada en la lucha para seguir implementando el "Programa de Acción Mundial para los Jóvenes hasta el año 2000 y años subsiguientes" ${ }^{22}$. Esta perspectiva internacional ilustra a la juventud como uno de los desafíos que prácticamente tienen todos los gobiernos democráticos.

Así, se advierta a la juventud como uno de los elementos determinantes de la geografía internacional y local, y especialmente representa uno de los baluartes donde se puede construir el andamiaje ciudadano e institucional para los nuevos espacios públicos del siglo XXI. Los jóvenes pues, se erigen como pieza clave en la implementación y cumplimiento de la Agenda de Desarrollo Sostenible post 2015; en dicha perspectiva, el Fondo de Población de las Naciones Unidas (UNFPA) ha reconocido que para alcanzar dichos objetivos es "fundamental erradicar la pobreza en todas sus formas, atajar la exclusión y la desigualdad y empoderar a los 1.800 millones de jóvenes del mundo. Por lo tanto, el bienestar y la participación social positiva de este grupo de adolescentes y jóvenes depende de los compromisos de los gobiernos para proteger sus derechos humanos, desarrollar sus capacidades, garantizar su salud sexual y reproductiva y sus derechos reproductivos, prepararlos para actividades productivas y creativas y recompensar su

\footnotetext{
${ }^{20}$ Organización de las Naciones Unidas, Informe sobre la juventud mundial 2005(Informe del Secretario General), Asamblea General. Consejo Económico y Social, 6 de diciembre de 2004, párrafo 6, (disponible en: http://www.cinu.mx/minisitio/UNjuventud/docs/A_60_61.pdf).

${ }^{21}$ Naciones Unidas. Resolución aprobada por la Asamblea General [sobre la base del informe de la Tercera Comisión (A/58/497 (Part II))] 58/133. Políticas y programas relativos a la juventud. Disponible en http://www.cinu.mx/minisitio/UNjuventud/docs/Resolucion58_133.pdf (consultado el 10 de junio de 2016).

${ }^{22}$ Naciones Unidas. Asamblea General. Resolución 50/81. Programa de Acción Mundial para los Jóvenes hasta el año 2000 y años subsiguientes. Constituye un documento de referencia internacional aún que estableció diez ejes prioritarios de trabajo a beneficio de los jóvenes, estos son: Educación. Empleo. El hambre y la pobreza. Salud . Medio ambiente. Uso indebido de drogas. Delincuencia juvenil. Actividades recreativas. Las niñas y las jóvenes. Plena y efectiva participación de los jóvenes en la vida de la sociedad y en la adopción de decisiones. Pero además estableció medios de cooperación a nivel nacional. regional e internacional para trabajar estos ejes. Para mayor información consultar http://www.cinu.mx/minisitio/UNjuventud/docs/Programa_accion_mundial_jovenes.pdf
} 
trabajo" 23 . La vertiente que plantea las Naciones Unidas son determinantes en las nuevas agendas públicas del mundo. Por ejemplo, una de los conceptos que han comenzado a circular en los modelos sociales, es el de "inversión en la juventud" que alude a las posibilidades que surgen cuando se aseguran de forma efectiva, los derechos de los jóvenes. Dicho con otras palabras, existe una relación estrecha entre derechos humanos de los jóvenes y desarrollo. IremTümer lo señala de forma exacta: "Aunque ya se ha consolidado la idea de que invertir en los jóvenes tiene sentido desde un punto de vista económico y es un imperativo de derechos humanos, a veces se olvida este último aspecto, sobre todo cuando se les pide que 'cambien el mundo'. El mundo no cambiará, por mucho que lo intentemos, si los jóvenes no pueden ejercer sus derechos humanos" ${ }^{24}$.En los últimos años el discurso sobre la juventud ha logrado articular un eje en el ámbito en la Agenda 2030: "Para el Desarrollo Sostenible supone una oportunidad única de incorporar políticas destinadas a los jóvenes en estrategias globales de desarrollo sostenible" 25 .

\section{a. Derechos políticos, derechos humanos y nuevas narrativas sociales}

En la perspectiva global, la caracterización de los derechos políticos de los jóvenes requiere una nueva perspectiva de los modelos regulatorios y de los propios principios que animan la ciencia jurídica.Por una parte, la forma en cómo los derechos han planteado nuevas agendas sociales y espacios públicos en América Latina, y gradualmente, la perspectiva de los derechos humanos se presenta como una opción cierta sobre los modelos democráticos. Es pues, la comprensión de las libertades juveniles un aspecto que anima el estudio de los derechos políticos desde diversos vértices. Movimientos juveniles, culturas juveniles, identidades políticas, entre otras.

Una nueva línea de trabajo en el ámbito de las metodologías y estudios juveniles, es la perspectiva de derechos humanos. Las razones que sustentan la afirmación merece algunos comentarios. En los últimos años en el continente americano, se han planteado agendas emergentes que han desarrollado nuevos ejes en las democracias latinoamericanas. Un aspecto que debe resaltarse de la nueva perspectiva jurídica de los derechos en la región, es que se ha tejido una nueva narrativa sobre el principio de universalidad de los derechos y se han creado auténticos corpus hermenéuticos sobre conceptos determinantes en la historia constitucional, tales como la noción de igualdad y el principio de dignidad. El nuevo tiempo de los derechos fundamentales en América Latina permitió el establecimiento de un nuevo lenguaje jurídico en donde se busca crear soluciones a violaciones de derechos, pero también a las razones estructurales que motivaron la falta de protección. En el célebre Caso Ximenes López vs Brasilde la Corte Interamericana de Derechos Humanos, se señaló la obligación del Estado para la protección de personas en estado de vulnerabilidad: "103. La Corte Interamericana considera que toda persona que se encuentre en una situación de vulnerabilidad es titular de una protección especial, en razón de los deberes especiales cuyo cumplimiento por parte del Estado es necesario para satisfacer las obligaciones generales de respeto y garantía de los derechos humanos. La Corte reitera que no basta que los Estados se abstengan de violar los derechos, sino que es imperativa la adopción de medidas positivas, determinables en función de las particulares necesidades de protección del sujeto de derecho, ya sea por su condición personal o por la

\footnotetext{
${ }^{23}$ UNFPA. Estado de la Población Mundial 2014. El poder de 1.800 millones. Los adolescentes, los jóvenes y la transformación del futuro. 2014. Pág.79-80. Disponible http://www.unfpa.org.mx/publicaciones/Reporte_Estado_de_la_Poblacion_Mundial_2014.pdf

${ }^{24}$ Tümer, Irem, "Mensaje", en UNFPA. Estado de la Población Mundial 2014. El poder de 1.800 millones. Los adolescentes, los jóvenes y la transformación del futuro, Op. cit., p. iv.

${ }_{25}$ Organización Internacional del Trabajo, Perspectivas sociales y de empleo en el mundo: Jóvenes (Tendencias del empleo juvenil 2016), Resumen ejecutivo, p. 4. (Disponible en: http://www.ilo.org/wcmsp5/groups/public/--dgreports/---dcomm/---publ/documents/publication/wcms_513747.pdf).
}

Revista de Direito Brasileira | São Paulo, SP | v. 19 | n. 8 | p. 250 - 275 |Jan./Abr. 2018 
situación específica en que se encuentre" ${ }^{26}$.Es pues, que el sistema interamericano ha empujado una nueva gramática de los derechos y su protección, al ir tejiendo nuevas reglas y estándares de sujetos que históricamente han sido marginados en sus derechos fundamentales.

\section{b. Derechos políticos y juventud}

Una forma de entender las libertades políticas de los jóvenes es a través de diversas formas alternativas de participación política, que en algunos casos, han encarnado procesos de indignación ciudadana. A pesar de que una idea que permeó los análisis en los últimos años, fue la apatía política y ciudadana, los jóvenes se han articulado en una protagonista en los grandes cambios democráticos de América Latina ${ }^{27}$. Se ha señalado que "la juventud es la expresión social de un grupo de edad que refleja una configuración particular en las relaciones sociopolíticas que entabla con los social, la cual se manifiesta en referentes e identificaciones particulares" (TEJERA GAONA, 2017, p. 30).Así, la perspectiva de los derechos políticos de la juventud son una referencia obligada en el debate social y político de América Latina.Como se ha planteado en este ensayo, un filón necesario en el análisis de los derechos políticos de los jóvenes es la perspectiva de derechos humanos. De tal suerte, se advierte cómo uno de los paradigmas que han sido ricos en América Latina, es el de los derechos humanos. Así, se analizará en este apartado diversos ejes de discusión en donde e sistema interamericano de derechos humanos ha sido pródigo: menuzar as características de las libertades políticas de la juventud. La tesis es sencilla. Los países de la región han confiado en los modelos de derechos humanos, como esquemas de democratización efectiva. Por ello, la visión será presentada desde esta perspectiva.

\section{c. Libertades políticas de los jóvenes}

En este contexto de luchas por la democracia, el horizonte de los derechos humanos, desde el ámbito nacional hasta llegar a los sistemas internacionales, ha permitido mostrar los derechos políticos desde una perspectiva holística. No tan solo desde el fraseo legal, sino desde otras posibles coordenadas que han permitido presentar a los derechos políticos nutridos desde la educación, la cultura de la legalidad, entre otros. Por ello, los jóvenes latinoamericanos se han constituido en los principales actores en las Américas, desde los movimientos sociales en contra de regímenes autoritarios o transiciones democráticas, y especialmente en detonadores de nuevos tiempos políticos.

La importancia de identificar la amplitud de derechos y el contenido de cada uno de ellos, posibilita un análisis más sólido para las propuestas y sobre todo, para contar con los lineamientos necesarios y su eventual incorporación en los diversos sistema democráticos y jurídicos de América Latina. Así han surgido nuevas expectativas políticas de jóvenes que han logrado posicionar un nuevo discurso político, vinculado en buena medida a las agendas mundiales de derechos humanos. Defensores de derechos humanos, candidatos independientes, bloggeros, internautas cansados de la política tradicional, y muchos otros, que han puesto en jaque a las maneras tradicionales de las democracias. Además, es claro que los principios que se han enarbolado en los últimos años, ha mostrado la relación de los derechos humanos:

\footnotetext{
${ }^{26}$ Corte IDH, Caso Ximenes López vs Brasil, Sentencia de 4 de julio de 2006, párrafo 103. (Disponible en: http://www.corteidh.or.cr/docs/casos/articulos/Seriec_149_esp.pdf).

27 Los jóvenes del mundo han logrado potenciar la agenda social del mundo. Por ejemplo, BanKin Moon, exsecretario General de la ONU, señaló en 2014: "Hoy en día, una persona de cada cinco tiene entre 15 y 24 años de edad. La transición de la juventud a la edad adulta nunca afrontó tantas dificultades, pero nunca tuvo tantas oportunidades. Tienen la facultad de relacionarse de una forma que habría sido inimaginable cuando se fundaron las Naciones Unidas hace casi 70 años. Se conectan para tratar cuestiones importantes. Injusticia. Discriminación. Violaciones de derechos humanos. El discurso del odio. La necesidad de la solidaridad humana". (Disponible en:http://www.un.org/es/events/democracyday/2014/sgmessage.shtml).
}

Revista de Direito Brasileira | São Paulo, SP | v. 19 | n. 8 | p. 250 - 275 |Jan./Abr. 2018 
Democracias con sistemas de transparencia efectiva, libertades políticas con derechos a salvo, como el de la movilización o protesta. Nuevas formas de participación política que han logrado incorporar las herramientas tecnológicas en los nuevos tiempos.

En este panorama se puede señalar el desarrollo de mecanismos de protección como el Sistema Interamericano de Derechos Humanos SIDH, cuyo principio rector es la democracia y por ende el ejercicio de los derechos civiles y políticos. Esta cuestión es determinante porque se advierte como los derechos políticos son fundamentales para perfilar las condiciones en que los ciudadanos participan en la cosa pública. La Carta Democrática de la Organización de los Estados Americanos consagra los elementos esenciales de la democracia: "Respeto a los derechos humanos y las libertades fundamentales; el acceso al poder y su ejercicio con sujeción al estado de derecho; la celebración de elecciones periódicas, libres, justas y basadas en el sufragio universal y secreto como expresión de la soberanía del pueblo; el régimen plural de partidos y organizaciones políticas; y la separación e independencia de los poderes públicas" (Art. 3$)^{28}$.

Asimismo, la Comisión Interamericana ha señalado la importancia de la "relación directa entre el ejercicio de los derechos políticos y el concepto de democracia como forma de organización del Estado y a continuación se ha referido a la necesidad de garantizar a los ciudadanos y a los grupos políticos organizados el derecho a reunirse públicamente, permitiendo y fomentando un debate amplio sobre la naturaleza de las decisiones políticas que requieren las medidas que adoptan los representantes elegidos por los ciudadanos" ${ }^{29}$.

Esta perspectiva planteada por el modelo interamericano evidencia uno de los principales reclamos de cualquier espacio democrático, establecer medidas capaces de incentivar la participación política, y en especial de promover el pluralismo político, en relación a efectivas políticas de igualdad y no discriminación.Se entiende la interrelación entre la tríada de "los derechos y libertades inherentes a la persona, sus garantías y el Estado de Derecho" ${ }^{30}$. Sumado a lo anterior, se debe destacar un aspecto que no siempre es claro del sistema interamericano. Por una parte, la importancia de sus órganos, como la Comisión y la Corte en la identificación de estándares de derechos humanos, pero especialmente el espíritu de establecer a través del respeto de los derechos, las condiciones mínimas para el establecimiento de efectivas reglas democráticas. Por ello, la Corte IDH ha señalado el rol de los derechos políticos en los paradigmas democráticos, ya "que el ejercicio efectivo de los derechos políticos constituye un fin en sí mismo y, a la vez, un medio fundamental que las sociedades democráticas tienen para garantizar los demás derechos humanos previstos en la Convención"31. Es pues, un factor inextricable de los modelos democráticos, derechos humanos y democracia.

\footnotetext{
${ }^{28}$ Carta Democrática Interamericana (Disponible en: http://www.oas.org/charter/docs_es/resolucion1_es.htm).

${ }^{29}$ Comisión IDH, Democracia y derechos humanos en Venezuela, 30 diciembre de 2009, párrafo 21. (Disponible en: http://www.cidh.org/countryrep/Venezuela2009sp/VE09.indice.sp.htm)

30 Así la Corte Interamericana señala: "Los Estados tiene la obligación de reconocer y respetar los derechos y libertades de la persona humana, así como proteger y asegurar su ejercicio a través de las respectivas garantías (artículo 1.1), medios idóneos para que aquéllos sean efectivos en toda circunstancia, tanto el corpus iuris de derechos y libertades como las garantías de éstos, son conceptos inseparables del sistema de valores y principios característica de la sociedad democrática", Corte IDH, Opinión Consultiva OC-17/2002 de 28 de agosto de 2002, párrafo 92 y 93, Disponible en: http://www.corteidh.or.cr/docs/opiniones/seriea_17_esp.pdf.

31 Corte IDH. Caso Castañeda Gutman Vs. Estados Unidos Mexicanos. Excepciones Preliminares, Fondo, Reparaciones y Costas. Sentencia de 6 de agosto de 2008. Serie C No. 184, Párrafo 143
} 


\section{EL SISTEMA INTERAMERICANO DE LA JUVENTUD}

\section{a. Los derechos políticos desde el sistema interamericano}

En América Latina, la Convención Americana establece el horizonte de los derechos políticos $^{32}$, en donde se destacan los contenidos mínimos en cuanto a la participación y el respeto al principio de igualdad. Los principios planteados por el sistema interamericano han advertido criterios determinantes en cuanto al alcance de dichas garantías cuando existen contextos de violencia generalizada, o de sujetos que por su condición de vulnerabilidad, carezcan de las oportunidades mínimas para ejercer sus derechos políticos.

Tradicionalmente las agendas políticas de la juventud estaban dictadas por perspectivas estatales, y gradualmente, el desarrollo de teorías sociales se consolidó una línea crítica: Reconocer desde principios, tales como ciudadanía o diversidad, la existencia de identidades políticas juveniles (BURAK, 2001, p. 25). Uno de los ejemplos determinantes, en donde se ha advertido un esquema complejo para el ejercicio de los derechos políticos, es el planteado por los pueblos y comunidades indígenas, en donde se considera que "las medidas de protección especial son necesarias e imperativas para que las comunidades indígenas puedan ejercer sus derechos efectivamente, en plano de igualdad con el resto de la población, y a fin de garantizar la supervivencia de los valores culturales y, en particular, las formas de participación política" ${ }^{33}$.

Asimismo, la Convención Iberoamericana de Derechos de los Jóvenes establece los derechos políticos juveniles ${ }^{34}$. El artículo 21 establece los lineamientos de los derechos políticos y obligaciones específicas de $\operatorname{los}$ Estados $^{35}$. Se destaca del precepto citado, la importancia que tienen las estrategias institucionales para incentivar las libertades políticas de los jóvenes. Es precisamente en este ámbito donde se advierten grandes desafíos para los gobiernos, porque se ha evidenciado la falta de consideración del contexto de las juventudes y sus derechos políticos.Un

\footnotetext{
${ }^{32}$ Comisión IDH. Documentos básicos en materia de derechos humanos en el Sistema Interamericano. Convención Americana sobre Derechos Humanos. Artículo 23:

1. Todos los ciudadanos deben gozar de los siguientes derechos y oportunidades:

a) de participar en la dirección de los asuntos públicos, directamente o por medio de representantes libremente elegidos;

c) de tener acceso, en condiciones generales de igualdad, a las funciones públicas de su país.

En el mismo sentido, se señala en el artículo 25 del Pacto Internacional de Derechos Civiles y Políticos. Adoptado por la Asamblea General en su resolución 2200 A (XXI), de 16 de diciembre de 1966: "Todos los ciudadanos gozarán, sin ninguna de la distinciones mencionadas en el artículo 2, y sin restricciones indebidas, de los siguientes derechos y oportunidades:a) Participar en la dirección de los asuntos públicos, directamente o por medio de representantes libremente elegidos;b) Votar y ser elegidos en elecciones periódicas, auténticas, realizadas por sufragio universal e igual y por voto secreto que garantice la libre expresión de la voluntad de los electores;c) Tener acceso, en condiciones generales de igualdad, a las funciones públicas de su país".

${ }^{33}$ Corte IDH, Caso Yatama vs. Nicaragua. Sentencia de 23 de junio de 2005 (Excepciones preliminares, fondo, reparaciones y costas), Párrafo 179 , inciso g.

${ }^{34}$ Convención Iberoamericana de Derechos de los Jóvenes. Artículo 21. Aprobada en Octubre 2005 por la Estados Miembros de la Organización Iberoamericana de Juventud. Disponible en http://www.oij.org/file_upload/publicationsItems/document/20120607115106_98.pdf

${ }^{35}$ Artículo 21. Participación de los jóvenes:

1. Los jóvenes tienen derecho a la participación política.

2. Los Estados Parte se comprometen a impulsar y fortalecer procesos sociales que generen formas y garantías que hagan efectiva la participación de jóvenes de todos los sectores de la sociedad, en organizaciones que alienten su inclusión.

3. Los Estados Parte promoverán medidas que de conformidad con la legislación interna de cada país, promuevan e incentiven el ejercicio de los jóvenes a su derecho de inscribirse en agrupaciones políticas, elegir y ser elegidos.

4. Los Estados Parte se comprometen a promover que las instituciones gubernamentales y legislativas fomenten la participación de los jóvenes en la formulación de políticas y leyes referidas a la juventud, articulando los mecanismos adecuados para hacer efectivo el análisis y discusión de las iniciativas de los jóvenes, a través de sus organizaciones y asociaciones.
} 
ejemplo. Muchos de los reclamos juveniles han nacido de una forma transnacional: "Los activistas del movimiento organizados alrededor de causas similares -por ejemplo, el medio ambiente, los derechos de las mujeres o la oposición a los talleres de confección de ropa en países pobres que trabajan para mercados ricos a cambio de unos salarios miserables- también han establecido unos contactos transcontinentales y transoceánicos duraderos" (TILLY Y WOOD, 2010, p. 225).

En la nueva forma transnacional de advertir nuevas expectativas políticas de los jóvenes, se advierte la crisis de modelos políticos tradicionales. En esta coyuntura, los jóvenes y sus inconformidades han articulado nuevas líneas de pensamiento críticas en el mundo social. Por ello, algunos autores han señalado la fuerza creadora de la inconformidad juvenil y de otros actores sociales: "El futuro de la democracia europea (e incluso mundial) está en manos de los movimientos sociales que han venido indignándose contra este estado de cosas, ocupando las calles y las plazas, ante la constatación de que la democracia institucional está ocupada por intereses minoritarios y antidemocráticos, y exigiendo una democracia real y verdadera"(DE SOUSA SANTOS, 2014, p. 20) ${ }^{36}$. Precisamente, los jóvenes han potenciado medios de comunicación que han visto su nacimiento en el ocaso del siglo $\mathrm{XX}$, redes sociales y todas las posibilidades que brinda la Web. Así, por ejemplo, el internet ha establecido nuevas formas de expresión y se han potenciado derechos de forma inmediata.

La Relatoría Especial para la Libertad de Expresión de la Comisión Interamericana ha señalado: "El entorno en línea no solo ha facilitado que los ciudadanos se expresen libre y abiertamente, sino que también ofrece condiciones inmejorables para la innovación y el ejercicio de otros derechos fundamentales como el derecho a la educación y a la libre asociación. Como lo ha sostenido la Asamblea General de la OEA, las tecnologías de la información y la comunicación (TIC) son cruciales para el desarrollo político, económico, social y cultural, así como un factor esencial para la reducción de pobreza, la creación de empleo, la protección ambiental y para la prevención y mitigación de catástrofes naturales" ${ }^{37}$.Esta nueva perspectiva digital para la juventud ha resultado especialmente atractiva para lograr crear nuevas agendas políticas y sociales a través de movimientos ciudadanos o de nuevas formas de acción política. En este sentido, la gran tensión que abre la regulación del internet, es la forma en cómo desde la regulación nacional se logra el respeto a la libertad de expresión en internet ${ }^{38}$.La tensión que se atisba de la regulación local frente a fenómenos transnacionales es evidente, que incluso se ha señalado un aspecto importante, las relaciones de comunicación entre los usuarios de internet podrían articular nuevas fronteras de un mundo nuevo. Timothy GartonAsh ha dicho en su Free Speech (Ten Principlesfor a ConnectedWorld)que los usuarios de Facebook podrían ser más numerosos que los habitantes de China ${ }^{39}$.

\footnotetext{
${ }^{36}$ Continúa el profesor portugués: "Fueron los movimientos sociales los que en la década de 2000 llevaron al poder a gobiernos progresistas en América Latina, gobiernos que le apostaron a crear mercados internos, promover alguna redistribución de la riqueza y, para eso, dispuestos a desobedecer las imposiciones de los mercados financieros y sus agencias" (DE SOUSA SANTOS, 2014, p. 20).

${ }^{37}$ Comisión IDH, Informe Anual de la Relatoría Especial para la Libertad de Expresión, 31 de diciembre de 2013, Párrafo 2 de la Introduccióndel Capítulo IV (Libertad de Expresión e Internet),Disponible en:http://www.oas.org/es/cidh/expresion/docs/informes/2014_04_22_ia_2013_esp_final_web.pdf (Consultado el 24 de enero de 2015) .

${ }^{38}$ De tal suerte, la Relatoría Especial ha destacado la labor de algunos países que han sido pioneros en la regulación de los derechos de internet. México, Chile, Brasil, por mencionar algunos países, han establecido en sus marcos regulatorios, estándares de derechos humanos, principalmente desde la perspectiva internacional, relativos a la libertad de expresión en internet. Comisión IDH, Informe Anual de la Relatoría Especial para la Libertad de Expresión, 31 de diciembre de 2013, Párrafos 5-9 de la Introduccióndel Capítulo IV (Libertad de Expresión e Internet).

${ }^{39}$ GARTON ASH, Timothy (2016), Free Speech (Ten Principles for a Connected World), USA, Yale University Press, p. 1.
} 
Es pues, que las bondades del internet son claras para los espacios juveniles y e fomento a la participación política y democrática.La propia Relatoría Especial de Libertad de Expresión ha delineado las características del Internet y su configuración especial al crear espacios de comunicación abiertos, democráticos y de fácil acceso que buscan ser universales y sin realizar discriminación alguna: "En la medida en que el entorno digital ofrece el espacio para promover el intercambio de información y opiniones, su configuración y arquitectura resultan relevantes. Internet se ha desarrollado a partir de determinados principios de diseño, cuya aplicación ha propiciado y permitido que el ambiente en línea sea un espacio descentralizado, abierto y neutral"40. Más adelante, en 2016, la Relatoría Especializada señaló la interdependencia y progresividad de los derechos humanos vinculados al internet: "Internet sirve de plataforma para la realización de otros derechos humanos como el derecho a participar en la vida cultural y a gozar de los beneficios del progreso científico y tecnológico (artículo 14 del Protocolo de San Salvador), el derecho a la educación (artículo 13 del Protocolo de San Salvador), el derecho de reunión y asociación (artículo 15 y 16 de la Convención Americana), los derechos políticos (artículo 23 de la Convención Americana), y el derecho a la salud (artículo 10 del Protocolo de San Salvador), entre otros" ${ }^{41}$. Como se puede advertir, gradualmente se va creando una narrativa en donde la juventud, compromiso político e internet, van complementándose. No es casual, que incluso se vaya formando una literatura sobre esta interacción evidente en la arena política. El textoYoung Citizens and New Media (LearningforDemocraticParticipation) coordinado por el profesor Peter Dahlgren ${ }^{42}$ recorre el compromiso político juvenil desde los nuevos medios de comunicación planetarios.

\section{b. La libertad de expresión juvenil}

Dentro de las libertades políticas de los jóvenes, la libertad de expresión se presenta como una de las herramientas determinantes en la construcción de su identidad y su forma de interacción en los espacios públicos. Ya hemos dicho en párrafos anteriores, cómo muchos de los reclamos de los jóvenes en América Latina han guiado agendas sociales indiscutibles. Los modelos políticos están en transición, y como señala MarysiaZalewski respecto a los derechos, "los tiempos en transición ofrecen esperanza para el cambio real" (ZALEWSKI, 2013, p. 362). Por ello, se puede afirmar que la libertad de expresión en el ámbito de la juventud se erige como un principio democrático sobre el cual debe estar fundado un Estado, ya que de esta manera se asegura nuevos debates y especialmente, la creación de sociedades más dialógicas. Por otra parte,la libertad de expresión se articula como condición para la realización de otros principios democráticos como la transparencia, en tanto principio de evaluación y rendición de cuentas de modelos democráticos. Por otra parte la libre circulación de ideas permite que el ciudadano pueda "formar un juicio sobre las cuestiones decisivas y cuando sabe lo bastante de la conducta de los gobernantes para poder aprobar o rechazar su gestión. Las libertades de expresión e información garantizan la existencia de una opinión pública libre y plural, siendo condición inexcusable para la existencia de una sociedad plural y democrática, sin la cual es impensable el respeto a la libertad de conciencia y a la dignidad de la persona"43. En este apartado se puede valorar la importancia de la libertad de expresión en las juventudes, porque si se promociona

\footnotetext{
${ }^{40}$ Comisión IDH, Informe Anual de la Relatoría Especial para la Libertad de Expresión, 31 de diciembre de 2013, Párrafo 11 de la Introducción del Capítulo IV (Libertad de Expresión e Internet).

${ }^{41}$ Comisión IDH, Informe Anual de la Comisión Interamericana de Derechos Humanos 2016, Informe de la Relatoría Especial para la Libertad de Expresión, Volumen II, Aprobado 15 de marzo de 2017,Párrafo 3 del Capítulo III (Estándares para una internet libre, abierta e incluyente).

${ }^{42}$ DAHLGREN, Peter (2007), Young Citizens and New Media (Learning for Democratic Participation), USA, Routledge, $262 \mathrm{p}$.

${ }^{43}$ Comisión IDH, Informe Anual 2004. Informe Anual de la Relatoría Especial para la Libertad de Expresión.
} 
adecuadamente la libertad de expresión desde temprana edad y especialmente en la juventud, se puede incidir en la creación de espacios públicos donde la cultura de la legalidad pueda ser el norte de los modelos latinoamericanos.

\section{c. Derecho a la reunión de los jóvenes}

El derecho a la reunión es uno de los componentes necesarios del ámbito de las expectativas y necesidades políticas de los jóvenes. La normativa sobre este importante derecho ha determinado una línea legislativa y jurisprudencial en el ámbito interamericano ${ }^{44}$, que incluso ha sido retomada por instrumentos específicos de los jóvenes ${ }^{45}$, que han establecido diversas coordenadas de acción institucional. Para la identificación de la libertad de reunión en el ámbito de la juventud es necesario considerar las características generales de dicha prerrogativa y su vinculación con otros derechos, como la libertad de expresión e información.

En esta parte del ensayo, es pertinente señalar una cuestión. Una de las preguntas que se han planteado en el ámbito de los derechos humanos en América Latina, es cómo en los contextos de violencia y desigualdad estructural, el Estado ha brindado respuesta a los reclamos ciudadanos. Normalmente la respuestaesencial de los sistemas institucionales, en el mejor de los casos, ha sido la producción legislativa.Sin embargo, una interrogante que resulta pertinente, es la realizada por Roberto Saba en su libro Más allá de la igualdad formal ante la ley, y que es el subtítulo de la obra, "¿Qué les debe el Estado a los grupos desaventajados?"46. Precisamente, los jóvenes han logrado establecer agendas políticas que exigen mejores condiciones de vida y aseguramiento efectivo de derechos. Así, la consideración del modelo interamericano en el ámbito de la participación de los jóvenes es destacable, sobre todo por la forma en cómo se han logrado proteger espacios públicos a través de la articulación de diversos derechos humanos y espacios de emergencia ciudadana juvenil.Uno de los fenómenos juveniles más evidentes en los espacios de América Latina ha sido el de las manifestaciones públicas. En este sentido, la Comisión IDH ha señalado: "Los sectores más empobrecidos de nuestro hemisferio confrontan políticas y acciones discriminatorias, su acceso a la información sobre la planificación y ejecución de medidas que afectan sus vidas diarias es incipiente y en general los canales tradicionales de participación para hacer públicas sus denuncias se ven muchas veces

\footnotetext{
${ }^{44}$ Convención Americana. Artículo 15. Derecho de Reunión. Se reconoce el derecho de reunión pacífica y sin armas. El ejercicio de tal derecho sólo puede estar sujeto a las restricciones previstas por la ley, que sean necesarias en una sociedad democrática, en interés de la seguridad nacional, de la seguridad o del orden públicos, o para proteger la salud o la moral públicas o los derechos o libertades de los demás. Asimismo, el Pacto Internacional de Derechos Civiles y Políticos, en su artículo 21, señala:" Se reconoce el derecho de reunión pacífica. El ejercicio de tal derecho sólo podrá estar sujeto a las restricciones previstas por la ley que sean necesarias en una sociedad democrática, en interés de la seguridad nacional, de la seguridad pública o del orden público, o para proteger la salud o la moral públicas o los derechos y libertades de los demás".

${ }^{45}$ La Convención Iberoamericana de Derechos de los Jóvenes. "Artículo 18. Libertad de expresión, reunión y asociación.

1. Los jóvenes tienen derecho a la libertad de opinión, expresión, reunión e información, a disponer de foros juveniles y a crear organizaciones y asociaciones donde se analicen sus problemas y puedan presentar propuestas de iniciativas políticas ante las instancias públicas encargadas de atender asuntos relativos a la juventud, sin ningún tipo de interferencia o limitación.

2. Los Estados Parte se comprometen a promover todas las medidas necesarias que, con respeto a la independencia y autonomía de las organizaciones y asociaciones juveniles, les posibiliten la obtención de recursos concursables para el financiamiento de sus actividades, proyectos y programas".

${ }^{46}$ Según el autor argentino, "el reconocimiento del principio de igualdad ante la ley -establecido en la Constitución Nacional- podría imponer al Estado obligaciones y deberes hacia los conciudadanos más desaventajados", SABA, Roberto (2016), Más allá de la igualdad formal ante la ley (Qué les debe el Estado a los grupos desaventajados), Argentina, Siglo XXI Editores, p. 20.
}

Revista de Direito Brasileira | São Paulo, SP | v. 19 | n. 8 | p. 250 - 275 |Jan./Abr. 2018 
cercenados" 47 .A continuación se analizarán diversos derechos vinculados a la participación juvenil y su perspectiva de derechos humanos.

\section{d. Manifestaciones sociales y nuevas emociones democráticas de la juventud}

Si bien, uno de los aspectos que los modelos democráticos han buscado cristalizar, es la efectiva democratización de los espacios públicos, los jóvenes han evidenciado desde la ejercicio de la libertad de expresión, agendas vinculadas a condiciones de bienestar social y derechos que están en discusión, como pobreza, género y migración, por mencionar algunos. En dicho contexto, se entiende la importancia de la libertad de expresión en el desarrollo efectivo de los modelos democráticos. Por ello, el sistema interamericano ha privilegiado la libertad de expresión como "piedra angular de cualquier sociedad democrática"48 y ha tejido una importante jurisprudencia,por parte de la Corte IDH, dotándola de una importancia relevante dentro de una sociedad democrática; así, ha dicho que "la libertad de expresión se inserta en el orden público primario y radical de la democracia y que no es concebible sin el debate libre y sin que la disidencia tenga pleno derecho de manifestarse" ${ }^{49}$. Otra cuestión importante, es que donde hay un ejercicio del derecho a través de la manifestación, la libertad de expresión se expresa a través de las movilizaciones, las cuales representan una forma de su ejercicio. El ejercicio de este derecho es imprescindible en el ámbito juvenil porqué una de las formas emblemáticas de la visión juvenil es a través de la manifestación política. Para la Relatoría para la Libertad de Expresión de la Comisión IDH "la movilización social se han constituido como herramienta de petición a la autoridad pública y también como canal de denuncias públicas sobre abusos o violaciones a los derechos humanos" ${ }^{50}$.

Asimismo, la participación política en manifestacionessocialespor parte de los jóvenes, como ejercicio de la libertad de expresión y de la libertad de reunión, consolida el buen funcionamiento del sistema democrático inclusivo de todos los sectores de la sociedad. Es decir, la existencia de movilizaciones muestra a sociedades donde existe un debate público amplio sobre la cosa pública. Asimismo, el Estado no sólo debe abstenerse de interferir con el ejercicio del derecho a la manifestación pacífica, sino que debe adoptar medidas para asegurar su ejercicio efectivo $^{51}$. Es pues, que la protección del derecho de reunión comporta no sólo la obligación del Estado de no interferir con su ejercicio, sino la obligación de adoptar, en ciertas circunstancias, medidas positivas para asegurarlo, por ejemplo, protegiendo efectivamente a los participantes de una manifestación contra la violencia física por parte de personas que puedan sostener opiniones opuestas $^{52}$. Es claro que las medidas de previsión y cuidado buscan darle protección a la integridad a los inconformes y que se abran espacios de discusión pública. Se abre una veta de análisis determinante en las expectativas juveniles. Las movilizaciones son un instrumento de la libertad de expresión y espacio de deliberación y diálogo democráticos.

\footnotetext{
${ }^{47}$ Continúa la Comisión IDH: "Ante este escenario en muchos países del hemisferio, la protesta y la movilización social se han constituido como herramienta de petición a la autoridad pública y también como canal de denuncias públicas sobre abusos o violaciones a los derechos humanos",Comisión IDH . Relatoría para la Libertad de Expresión. Informe Anual 2005. Capitulo V_ Las Manifestaciones P1 crh v úblicas Como Ejercicio De La Libertad De Expresión Y La Libertad De Reunión. párrafo 1 .

${ }^{48}$ Comisión IDH, Libertad de expresión e internet (Relatoría Especial para la Libertad de Expresión), 2013, párrafo 1. Disponible en http://www.oas.org/es/cidh/expresion/docs/informes/2014_04_08_Internet_WEB.pdf (Consultado el 3 de enero de 2016).

${ }^{49}$ Corte IDH. Opinión Consultiva OC-5/85. La colegiación obligatoria de periodistas. Párrafo 69

${ }^{50}$ Comisión IDH . Relatoría para la Libertad de Expresión. Informe Anual 2005. Capitulo V_ Las Manifestaciones P1 crh v úblicas Como Ejercicio De La Libertad De Expresión Y La Libertad De Reunión. párrafo 1

${ }^{51}$ Comisión IDH. Democracia y Derechos Humanos en Venezuela. 2009.párrafo 118

${ }^{52}$ ión IDH. Democracia y Derechos Humanos en Venezuela. 2009.párrafo 136
} 
Por otra parte, siendo las movilizaciones un canal de denuncias públicas, permite "el intercambio de ideas y reivindicaciones sociales como forma de expresión, supone el ejercicio de derechos conexos, tales como el derecho de los ciudadanos a reunirse y manifestar, y el derecho al libre flujo de opiniones e información" ${ }^{53}$. En este sentido, el artículo 15 de la CADH asegura que "se reconoce el derecho de reunión pacífica y sin armas. El ejercicio de tal derecho sólo puede estar sujeto a las restricciones previstas por la ley, que sean necesarias en una sociedad democrática, en interés de la seguridad nacional, de la seguridad o del orden públicos, o para proteger la salud o la moral públicas o los derechos o libertades de los demás" ${ }^{54}$.

Por otra parte, el sistema universal de derechos humanos ha destacado la importancia del derecho a la reunión pacífica y de asociación en tanto "sirven de cauce para el ejercicio de muchos otros derechos civiles, culturales, económicos, políticos y sociales, y son elementos esenciales de la democracia, pues mediante su ejercicio los hombres y las mujeres pueden expresar sus opiniones políticas, participar en proyectos literarios y artísticos y en otras actividades culturales, económicas y sociales, participar en cultos religiosos o practicar otras creencias, fundar sindicatos y afiliarse a ellos, y elegir dirigentes que representen sus intereses y respondan de sus actos" (resolución 15/21 del Consejo, preámbulo).Laamplitud de las posibilidades del ejercicio de los derechos comentados, plantean la necesidad de destacar un modelo de derechos humanos que gradualmente va dándole a los movimientos ciudadanos, y con especial atención a los juveniles, un lugar en los paradigmas políticos contemporáneos. Con otras palabras. La perspectiva de juventud en el ámbito de los derechos políticos, identifica una de las especificidades de las esperanzas democráticas del nuevo milenio, la movilización juvenil como un instrumento de las democracias contemporáneas.

Finalmente, considerando la interdependencia e interrelación existentes con otros derechos, la libertad de reunión pacífica y de asociación constituyen un valioso indicador para determinar en qué medida los Estados respetan el disfrute de muchos otros derechos humanos ${ }^{55}$.

\section{e. El derecho de reunión y su contenido}

Las posibilidades que brinda el derecho de reunión merece algunos comentarios. En primer lugar, la garantíadeeste derecho, establece obligaciones a los Estados de establecer marcos normativos que regulen el acceso a los espacios públicos; dicha regulación no debe entenderse en el sentido de limitar el derecho sino bajo la premisa que para garantizar el derecho se debe normar el ejercicio del mismo. Además, la Comisión IDH ha delineado las actividades que el Estado puede regular: Por ejemplo, el uso del espacio público fijando, requisitos de aviso previo; sin embargo, dichas regulaciones deben tener como finalidad la protección adecuada de los participantes de la manifestación, así como también la adopción de medidas conducentes a facilitar el ejercicio del derecho a la manifestación sin entorpecer de manera significativa el desarrollo normal de las actividades del resto de la comunidad. En este sentido, la regulación del uso del espacio público no puede comportar exigencias que restrinjan excesivamente el ejercicio del derecho a la manifestación pacífica y su finalidad no puede ser la de crear una base para que la reunión o la manifestación sea prohibida. Es más, la exigencia de una notificación previa no debe ser confundida con la exigencia de un permiso previo otorgado discrecionalmente.

\footnotetext{
${ }^{53}$ Comisión IDH . Relatoría para la Libertad de Expresión. Informe Anual 2005. Capitulo V_ Las Manifestaciones Públicas Como Ejercicio De La Libertad De Expresión Y La Libertad De Reunión. párrafo 5

${ }^{54}$ Convención Americana sobre Derechos Humanos. Artículo 15

${ }^{55}$ Instituto Nacional de Derechos Humanos. Alto Comisionado de las Naciones Unidas para los Derechos Humanos (ACNUDH). Protesta Social y Derechos Humanos: Estándares Internacionales y Nacionales. Primera edición. Santiago de Chile. 2014.Pág 34
}

Revista de Direito Brasileira | São Paulo, SP | v. 19 | n. 8 | p. 250 - 275 |Jan./Abr. 2018 
Asimismo, se pueden señalar argumentos importantes en el ámbito del derecho internacional de los derechos humanos sobre los derechos humanos analizados. El Relator para la reunión pacífica y derecho de asociación y el Relator sobre ejecuciones extrajudiciales del sistema de Naciones Unidas han expresado que "las restricciones relativas al "tiempo, lugar y modo" se refieren a las restricciones previas sobre cuándo, dónde y cómo se celebrará la reunión. Esas restricciones no deberían utilizarse nunca para socavar el mensaje o el valor expresivo de una reunión, ni para disuadir del ejercicio del derecho a la libertad de reunión" ${ }^{56}$.Otro tipo de restricciones se encuentran asociadas al contenido o mensaje que se desee transmitir, lo que puede entrar en confrontación directa con el ejercicio de la libertad de expresión.

Es pues, que el derecho a la reunión en el ámbito juvenil es una de las figuras que acompañan los movimientos sociales contemporáneos. Así, se advierte la importancia de una adecuada perspectiva de derechos humanos de los movimientos y movilizaciones juveniles. Por ello, las aportaciones de derechos humanos que se han dado en el ámbito de las movilizaciones han logrado evidenciar la importancia de identificar los principios que las integran.Las regulaciones de las manifestaciones públicas pueden ser de distintos tipos. Por un lado, existe la regulación legislativa, es decir, aquellos actos legislativos que restringen ya sea la hora, el lugar o la manera en la que se puede llevar a cabo una manifestación, sobre la base de que el derecho a usar las calles, los parques o las plazas no es completamente ilimitado. En ese sentido, la Relatoría de Libertad de Expresión ha considerado que para que dichas limitaciones respeten los estándares de protección de la libertad de expresión y de la libertad de reunión, no deben depender del contenido de lo que se vaya a expresar a través de la manifestación, deben servir un interés público y dejar otras vías alternativas de comunicación ${ }^{57}$

Finalmente, los estándares interamericanos en relación a las movilizaciones sociales, y en la relación con la libertad de expresión, han determinado que son tres los discursos que no podrían ser contenido o mensaje de una manifestación pública, estos son: a) la propaganda de la guerra y la apología del odio que constituya incitación a la violencia; b) La incitación directa y pública al genocidio, y c) La pornografía infantil. Como se advierte, las expectativas juveniles tienen una base cierta en la protección de sus reclamos ciudadanos y un coto objetivamente identificado.

\section{f. Juventud y criminalización de la protesta social}

Uno de las características del desarrollo de las expectativas juveniles en América Latina, son los espacios públicos creados por sus movilizaciones sociales y la creación de nuevos procesos democráticos. Ya se ha señalado que dichas movilizaciones poseen una perspectiva de derechos humanos que resulta necesario identificar.En este sentido, la regulación de derechos a la participación, de reunión e incluso de libertad de expresión se encuentran usualmente en tensión constante frente al ejercicio del poder público por parte del Estado. El desbordamiento social en el ejercicio de estos derechos, que podrían trastocar su contenido, hacen más complejo el escenario. Otras tensiones se producen por la falta de capacidad de los Estados de resistir una crítica abierta con motivo de su desempeño, estas tensiones producen como reacción la criminalización tanto de la libertad de expresión como del derecho a la reunión pacífica.

\footnotetext{
${ }^{56}$ ONU. Asamblea General A/HRC/31/66. Consejo de Derechos Humanos. $31^{\text {er }}$ período de sesiones. Informe conjunto del Relator Especial sobre los derechos a la libertad de reunión pacífica y de asociación y el Relator Especial sobre las ejecuciones extrajudiciales, sumarias o arbitrarias acerca de la gestión adecuada de las manifestaciones. 4 de febrero de 2016

Párrafo 34.

${ }^{57}$ Comisión IDH. Las Manifestaciones Públicas Como Ejercicio De La Libertad De Expresión Y La Libertad De Reunión, Op. cit., Párrafo 94
} 
La criminalización de la protesta social no es más que la utilización del poder público y en específico del derecho penal para reprimir el ejercicio de los derechos y por ende acallar las voces que le resultan incomodas a los Estados. En el ámbito juvenil se advierte la importancia del desarrollo de nuevos espacios públicos y especialmente en la protesta social y en muchos casos la condena que han recibido múltiples acciones juveniles. Dos cuestiones han sido consideradas dentro de la consideración de la protesta social. La importancia histórica que ha tenido las protestas para la reivindicación de reclamos políticos y sociales ${ }^{58}$, pero especialmente en los últimos años, y teniendo como protagonistas a los jóvenes, la denuncia de malos gobiernos y de aseguramiento de derechos básicos. En este sentido, la Comisión de Derechos Humanos del Distrito Federal ha destacado: "Históricamente la población joven ha sido identificada con una postura divergente respecto de las pautas y normas sociales culturalmente dominantes, lo que ha contribuido en gran medida a la construcción de categorizaciones y estigmas negativos alrededor de su pensamiento y acciones. Ejemplo de ello es la constante asociación que se realiza entre juventud y la inmadurez, la falta de compromiso, el uso de drogas, además de otras características negativas. Incluso se ha llegado a señalar a las y los jóvenes como causantes del clima de inestabilidad social, inseguridad y delincuencia" ${ }^{59}$. Sin embargo, a pesar de los múltiples obstáculos cada vez se establece una nueva vertiente en el ámbito de los derechos humanos. La protesta social puede ser una herramienta fundamental en los espacios democráticos.

Es pues, que la protesta social es un elemento esencial de las democracias latinoamericanas y de la consecución de nuevos espacios de debate y diálogo sociales.El Alto Comisionado de Derechos Humanos, Oficina Regional para América del Sur, ha logrado resumir la importancia de la protesta social como un derecho inexorable de los modelos democráticos: "No cabe sino concluir que, cuando el derecho a la protesta pacífica es protegido y ejercido de forma adecuada, es una herramienta poderosa para promover el diálogo, el pluralismo, la tolerancia y la participación cívica. Los seres humanos necesitan reunirse y expresarse, trabajar juntos por el bien común, hacer a sus líderes responsables y pedirles rendición de cuentas. estos derechos como tales no fomentan la violencia. Por el contrario, nos resguardan de ella. Ignorar las reivindicaciones ya no es una opción. Es hora de escucharlas, tenerlas en cuenta y avanzar hacia la sociedad de derechos que se ha prometido construir" ${ }^{60}$. Lo que advierte la protesta pues, es un ciudadano activo y dispuesto a establecer nuevos canales de comunicación con los actores gubernamentales. Sin embargo, se requiere contar con estándares mínimos que puedan ser asegurados por los estados para lograr establecer un adecuado marco a los derechos de expresión, reunión y asociación.

En los últimos años han aumentado los esfuerzos por tejer un sistema que establezca los ejes del respeto de los derechos humanos en las movilizaciones ciudadanas, protesta y libertad de expresión. En la actualidad, es moneda corriente la movilización juvenil en los países latinoamericanos $^{61}$, y en algunos casos se ha presentado la criminalización como una huella

\footnotetext{
58 "A lo largo de la historia las protestas sociales han sido motores de importantes cambios. La denegación de derechos, tanto civiles y políticos como económicos, sociales y culturales, ha dado origen a diversos movimientos de protesta, los que han promovido la caída de dictaduras, el voto universal, el fin de la esclavitud, el fin del apartheid y la reparación a víctimas, entre otros muchos logros", Alto Comisionado de las Naciones Unidas para los Derechos Humanos, Representante Regional para América del Sur, Protesta social y derechos humanos: Estándares internacionales y nacionales, ACNUDH, Chile, 2015, p. 11. Disponible en: http://acnudh.org/wpcontent/uploads/2015/04/PROTESTA-SOCIAL.pdf (Consultado el 12 de enero de 2017).

${ }^{59}$ Comisión de Derechos Humanos del Distrito Federal, Informe especial sobre los derechos humanos de las y los jóvenes en el Distrito Federal, Op. cit., p. 69.

${ }^{60}$ Alto Comisionado de las Naciones Unidas para los Derechos Humanos, Representante Regional para América del Sur, Protesta social y derechos humanos: Estándares internacionales y nacionales, Op. cit., p. 13.

${ }^{61}$ Tan solo en la Ciudad de México, 2013, se registraron "un total 5464 marchas y manifestaciones de las cuales 2731 correspondieron a temas del ámbito federal (49.9\%), mientras que 2733 estuvieron relacionadas con problemáticas exclusivas del Distrito Federal $(50.1 \%)$. Lo anterior permite sostener que el establecimiento de los Poderes de la Unión en el Distrito Federal, hoy por hoy, no puede considerarse como una causa exclusiva que justifique la Revista de Direito Brasileira | São Paulo, SP | v. 19 | n. 8 | p. 250 - 275 |Jan./Abr. 2018
} 
constante en la denuncias juveniles. La violación de derechos humanos, en la represión de movimientos juveniles, como en el Caso Ayotzinapa en México, han iniciado en la criminalización de las denuncias juveniles ${ }^{62}$. Más aún, "las manifestaciones, protestas y las demás formas de acción colectiva que tienen lugar en América Latina poseen como común denominador las agendas reivindicativas sociales. En términos generales, la ciudadanía está demandando más a las democracias, exigiendo mejores niveles de participación, transparencia, no discriminación y mayor acceso a derechos esenciales como la salud, educación, medio ambiente, seguridad e igualdad. De igual manera, la afectación del derecho de participación y a la consulta previa con pueblos indígenas ha producido movilizaciones sociales de distinta magnitud e intensidad en la región"63. Una conclusión evidente es este apartado es cómo la protesta juvenil puede considerarse como una de las principales herramientas en la reivindicación de los derechos humanos en los modelos democráticos contemporáneos ${ }^{64}$.

De lo anterior, se advierte la importancia de identificar las aportaciones del sistema internacional de los derechos humanos para establecer estándares mínimos que aseguren su realización y que otorgue seguridad a los participantes de ellas. Como se ha venido señalando, la identificación del contenido de los derechos humanos más pertinentes de los jóvenes, establecen un manual de acción para las juventudes en México y la región. Es claro que la protesta se ha presentado como uno de los derechos humanos que más análisis requieren en el ámbito juvenil. El punto de partida del respeto al derecho a la protesta se encuentra en el respeto a diversos derechos que incluyen la libertad de expresión y opinión, la libertad de asociación y la libertad de reunión pacífica. Sin embargo, la línea que debe considerarse en el análisis, es cuando dichos derechos pueden ser considerados excesivos frente a la paz pública.

La Relatoría sobre Libertad de Expresión de la Comisión IDH ha razonado la importancia de los derechos que involucran las movilizaciones sociales y la forma en que se debe considerar su respeto: "Resulta en principio inadmisible la penalización per se de las demostraciones en la vía pública cuando se realizan en el marco del derecho a la libertad de expresión y al derecho de reunión. Es importante recordar que la penalización podría generar en estos casos un efecto amedrentador sobre una forma de expresión participativa de los sectores de la sociedad que no pueden acceder a otros canales de denuncia o petición como la prensa tradicional o el derecho de petición. El amedrentamiento a la expresión a través de la imposición de penas privativas de la libertad para las personas que utilizan el medio de expresión antes

importante cantidad de marchas y manifestaciones que se desarrollan en la Ciudad de México, sino que hay otros factores sociales y políticos que deben ser analizados al intentar generar soluciones y políticas para atender dicho fenómeno", Comisión de Derechos Humanos del Distrito Federal, Manifestación, movilidad y derechos humanos: una propuesta de aproximación desde los estándares internacionales, Naciones Unidas Derechos Humanos (Oficina del Alto Comisionado)-INDH, Santiago de Chile, 2014, p. 7. Disponible en: http://acnudh.org/wpcontent/uploads/2015/04/PROTESTA-SOCIAL.pdf

${ }^{62}$ Sobre el Caso Ayotzinapa, véase CRUZ MARTÍNEZ, Mario, "Ayotzinapa. La nueva geometría de los derechos humanos de la juventud en México, en Estudios en Derechos Humanos, Derecho Constitucional y Libertad Religiosa (Libro-Homenaje a Raúl González Schmal), México, Porrúa, pp. 269-292.

${ }^{63}$ Alto Comisionado de las Naciones Unidas, Oficina Regional para América del Sur, Directrices para la observación de manifestaciones y protestas sociales, ACNUDH, p. 8. Disponible en: http://www.sdh.gov.br/sobre/participacao-social/cndh/relatorios/directrices-para-la-observacion-de-manifestacionesy-protestas-sociales (Consultado el 24 de abril de 2016).

${ }^{64}$ El Informe a la Asamblea General presentado por la Sra. HinaJilani, Representante Especial del Secretario General sobre la cuestión de los defensores de los derechos humanos, A/62/225 de 2007 sobre el derecho a la protesta en el contexto del derecho a la libertad de reunión pacífica señala: "A lo largo de la historia las protestas y manifestaciones han sido motores de cambio y factores importantes que contribuyeron a la promoción de los derechos humanos. En todas las regiones del mundo y en todas las épocas de la historia, defensores anónimos y activistas han liderado e inspirado movimientos de protesta que prepararon el terreno para los logros conseguidos en la esfera de los derechos humanos", en Alto Comisionado de las Naciones Unidas para los Derechos Humanos, Representante Regional para América del Sur, Protesta social y derechos humanos: Estándares internacionales y nacionales, Op. cit., p. 320.

Revista de Direito Brasileira | São Paulo, SP | v. 19 | n. 8 | p. 250 - 275 |Jan./Abr. 2018 
mencionado, tiene un efecto disuasivo sobre aquellos sectores de la sociedad que expresan sus puntos de vista o sus críticas a la gestión de gobierno como forma de incidencia en los procesos de decisiones y políticas estatales que los afecta directamente" ${ }^{\text {. }}$. Sin embargo, las movilizaciones deben cumplir ciertos requisitos específicos. "Ahora, si bien resulta admisible la penalización de actos de protesta violenta, debe estar estrictamente definida por la ley y operar de conformidad con criterios de proporcionalidad y bajo la premisa de que lo que puede ser objeto de reproche penal es el uso de la violencia, no el acto de protestar. Además, es preciso que la respuesta penal sea proporcional a la entidad del derecho afectado porque, de lo contrario, se genera una criminalización ilegítima de la protesta" ${ }^{66}$.

De lo anterior, se puede colegir diversas obligaciones del Estado para hacer efectivo el ejercicio de reunión pacífica y que se lleve a cabo sin violencia mediante el resguardo de las autoridades. En este sentido, los relatores sobre los derechos a la libertad de reunión pacífica y de asociación y sobre las ejecuciones extrajudiciales, sumarias o arbitraria de la ONU, han recordado que "aunque los organizadores deberían hacer todo lo posible por cumplir la ley y alentar la celebración pacífica de reuniones, no deben ser considerados responsables del comportamiento ilícito de otras personas. Si así se hiciera, se vulneraría el principio de responsabilidad individual, se debilitaría la confianza y la cooperación entre los organizadores de las concentraciones, los participantes y las autoridades, y se desalentaría a los organizadores potenciales de reuniones de ejercer sus derechos. No debería suscitarse la responsabilidad penal, civil o administrativa de ninguna persona por el mero hecho de organizar una protesta pacífica o participar en ella" ${ }^{67}$.

La Comisión de Derechos Humanos del Distrito Federal al analizar el derecho a la manifestación pacífica y la violencia que se pueda producir, ha establecido que "los actos violentos que se cometan de manera aislada en contextos de manifestación deben ser problematizados y resueltos de manera independiente, tomando las medidas necesarias para evitarlos, siempre desde un enfoque de derechos humanos y tomando en cuenta que su corrección está encaminada al cumplimiento de la obligación de protección del Estado. De esta manera, no resultaría válido restringir el derecho de manifestación pacífica con el argumento de enfrentar los actos de quienes no se manifiestan pacíficamente; por el contrario, las autoridades capitalinas deben generar escenarios de protección para asegurar el ejercicio del derecho de reunión y manifestación con el objetivo de evitar que puedan realizarse actos de violencia que atenten contra la integridad de los manifestantes, así como de la integridad, patrimonio o comercios de terceras personas" ${ }^{68}$.

\footnotetext{
${ }^{65}$ Comisión IDH. Relatoría para la Libertad de Expresión. La Agenda de la Relatoría Especial para la Libertad de Expresión: problemas persistentes y desafíos emergentes. Párrafo 32. disponible en www.cidh. oas.org/relatoria/showDocument.asp?DocumentID $=212$

${ }^{66}$ Uprimny, Rodrigo . Sánchez Duque, Luz María. Derecho penal y protesta social en Es legítima la criminalización de la protesta social? : derecho penal y libertad de expresión en América Latina / compilado por Eduardo Andrés Bertoni. - 1a ed. - Buenos Aires : Universidad de Palermo - UP, 2010. párrafo 26-27.

${ }^{67}$ ONU. Asamblea General A/HRC/31/66. Consejo de Derechos Humanos. $31^{\text {er }}$ período de sesiones. Informe conjunto del Relator Especial sobre los derechos a la libertad de reunión pacífica y de asociación y el Relator Especial sobre las ejecuciones extrajudiciales, sumarias o arbitrarias acerca de la gestión adecuada de las manifestaciones. 4 de febrero de 2016, Párrafo 33

${ }^{68}$ Comisión de Derechos Humanos del Distrito Federal. Manifestación, movilidad y derechos humanos: una propuesta de aproximación desde los estándares internacionales. Propuesta General 01. Diciembre 2013. Pág.19
} 


\section{REFLEXIONES FINALES}

Como se ha advertido en el desarrollo del presente ensayo, la temática juvenil es una de las principales cuestiones de las agendas democráticas de América Latina en la época contemporánea. Sin embargo, la escasa regulación y protección institucional de sus derechos, es contraria a la amplitud de los sujetos y la importancia que debería tener en cualquier esquema democrático. Precisamente, los jóvenes han sido considerados, desde ciertas teorías sociales,como personas que se encuentran en una etapa intermedia, de la infancia a la adultez, y por ello, su estudio ha sido más bien escaso. La propuesta que ha planteado este texto, es que además de la rica literatura social que se ha encargado de establecer la complejidad del sujeto joven, la perspectiva de derechos humanos, resulta una propuesta determinante para la protección de sus derechos políticos.

De lo anterior, se advierten un buen número de hallazgos, que podrán ser el punto de partida de investigaciones posteriores. A continuación se señalan algunos:

- El sujeto joven puede ser considerado desde la perspectiva de los derechos humanos, al presentar características de grupos sociales en estado de vulnerabilidad, y al enfrentar procesos de desigualdad estructural.

-La literatura juvenil evidencia la necesidad de contar con metodologías diversas para identificar las necesidades de las juventudes. De lo anterior, se han advertido cuestiones, tales como cultura juvenil, participación y compromiso político de los jóvenes.

- Los derechos políticos de los jóvenes y su ejercicio, están estableciendo nuevas agendas sociales. Esto, porque en el ejercicio de sus libertades políticas, las juventudes han denunciado la falta efectiva de procesos de democratización, pero especialmente, se han denunciado los modelos económicos y han abierto una agenda de justicia social. Entre los reclamos de los jóvenes, resuenan reclamos que van desde empleos y salarios justos, hasta política de seguridad pública, como en el movimiento estadounidense, NeverAgain.

- El sistema interamericano de derechos humanos es una auténtica caja de herramientas para la reivindicación de las libertades políticas de los jóvenes, ya que cuenta con un amplio caudal de principios, sobre libertad de expresión, reunión, manifestación, entre otros.

Finalmente, como se ha visto en el desarrollo del presente ensayo, a través del respeto de los derechos políticos de los jóvenes se podrán rediseñar los espacios públicos de América Latina e incentivar la efectiva justicia social de las democracias del mañana.

\section{BIBLIOGRAFÍA MÍNIMA}

\section{a. Literatura}

- ÁVALOS GONZÁLEZ, Juan Manuel (2015), "Numeralia sobre la condición juvenil contemporánea", en El sistema es antinosotros (Culturas, movimientos y resistencias juveniles), México, Gedisa, 505 p.

-BACA TAVIRA, Norma (2018), Juventudes (Género y salud reproductiva. Realidades, expectativas y retos), México, Gedisa, $370 \mathrm{p}$.

- BURAK, Solum Donas (2001), “Adolescencia y juventud (Viejos y nuevos desafíos en los albores del nuevo milenio", en Adolescencia y juventud en América Latina, Costa Rica, Libro Universitario Regional, pp. 23-40. 
- CRUZ MARTÍNEZ, Mario (2017), "El nuevo rostro de la ciudadanía en México frente al Estado de Derecho: los jóvenes y Ayotzinapa", en Perspectivas de los desafíos del Estado de Derecho en el México del Siglo XXI, México, Tirant Lo Blanch, pp. 117-156.

- CRUZ MARTÍNEZ, Mario (2018), Los derechos humanos de los jóvenes (De la vulnerabilidad a la imaginación de los derechos), Tirant Lo Blanch, México, 315 p.

- CRUZ MARTÍNEZ, Mario (2017), "Ayotzinapa. La nueva geometría de los derechos humanos de la juventud en México, en Estudios en Derechos Humanos, Derecho Constitucional y Libertad Religiosa (Libro-Homenaje a Raúl González Schmal), México, Porrúa, pp. 269-292.

- DAHLGREN, Peter (2007), Young Citizens and New Media (Learning for Democratic Participation), USA, Routledge, 262 p.

- FEIXA PÁMPOLS, Carles (2000), "Los espacios y los tiempos de las culturas juveniles", en Aproximaciones a la diversidad juvenil, México, Colegio de México, p. 45-60 .

- GARTON ASH, Timothy (2016), Free Speech (Ten Principles for a Connected World), USA, Yale University Press, 491 p.

- MEDINA CARRASCO, Gabriel (2000), Aproximaciones a la diversidad juvenil, México, Colegio de México.

- PNUD, La democracia en América Latina (Hacia una democracia de ciudadanas y ciudadanos), Programa de Naciones Unidas, 2004. Disponible en: http://www2.ohchr.org/spanish/issues/democracy/costarica/docs/PNUD-seminario.pdf).

- REGUILlO, Rossana (2012), Culturas juveniles (Formas políticas del desencanto), México, Siglo XXI editores, $187 \mathrm{p}$.

- REGUILLO, Rossana (2000), "Las culturas juveniles: Un capo de estudio. Breve agenda para la discusión", en Aproximaciones a la diversidad juvenil, México, Colegio de México, pp. 19-43.

-TEJERA GAONA, Héctor (2017), "Participación y cultura: la comparación entre jóvenes y adultos", en La cultura política de los jóvenes, México, Colegio de México, pp. 25-94.

-TILLY, Charles, y WOOD, Lesley (2010),Los movimientos sociales, 1768-2008 (Desde sus orígenes a Facebook), España, Crítica, 366 pp.

- VAN DE VELDE, Cécile, Devenir adulte (Sociologiecomparée de la jeunesse en Europe) (2008), Francia, PUF, 278 p.

\section{b. Instrumentos Internacionales y Jurisprudencia Interamericana}

- Alto Comisionado de las Naciones Unidas, Oficina Regional para América del Sur, Directrices para la observación de manifestaciones y protestas sociales, ACNUDH. Disponible en: $\quad$ http://www.sdh.gov.br/sobre/participacao-social/cndh/relatorios/directrices-para-laobservacion-de-manifestaciones-y-protestas-sociales 
- Carta Democrática Interamericana. Organización de los Estados Americanos. 11 de $\begin{array}{lll}\text { septiembre de } & 2001 .\end{array}$ Lima, Perú. Disponible en: http://www.oas.org/charter/docs_es/resolucion1_es.htm

- Convención Americana sobre Derechos Humanos.7 al 22 de noviembre de 1969, San José, Costa Rica. Disponible en:https://www.oas.org/dil/esp/tratados_b32_convencion_americana_sobre_derechos_humanos.htm

- Convención Iberoamericana de Derechos de los Jóvenes. 11 de octubre de 2005, Badajoz, España. Disponible en: http://www.crin.org/en/docs/FileManager/cidjpdf.pdf

- Corte IDH. Caso "La Última Tentación de Cristo" (Olmedo Bustos y otros) Vs. Chile. (Fondo, Reparaciones y Costas). Sentencia de 5 de febrero de 2001. Serie C No. 73. Disponible en: http://www.corteidh.or.cr/docs/casos/articulos/Seriec_73_esp.pdf

- Corte IDH. Caso Castañeda Gutman Vs. Estados Unidos Mexicanos. (Excepciones Preliminares, Fondo, Reparaciones y Costas). Sentencia de 6 de agosto de 2008. Serie C No. 184. Disponible en: http://www.corteidh.or.cr/docs/casos/articulos/seriec_184_esp.pdf

- Corte IDH. Caso Claude Reyes y otros Vs. Chile. (Fondo, Reparaciones y Costas). Sentencia de 19 de septiembre de 2006. Serie C No. 151. Disponible en: http://www.corteidh.or.cr/docs/casos/articulos/seriec_151_esp.pdf

- Corte IDH. Caso Escher y otros Vs. Brasil. (Excepciones Preliminares, Fondo, Reparaciones y Costas). Sentencia de 6 de julio de 2009. Serie C No. 200. Disponible en: http://www.corteidh.or.cr/docs/casos/articulos/seriec_200_esp1.pdf

- Corte IDH. Caso Granier y otros (Radio Caracas Televisión) Vs. Venezuela. (Excepciones Preliminares, Fondo, Reparaciones y Costas). Sentencia de 22 de junio de 2015. Serie C No. 293. Disponible en: http://www.corteidh.or.cr/docs/casos/articulos/seriec_293_esp.pdf

- Corte IDH. Caso Herrera Ulloa Vs. Costa Rica. (Excepciones Preliminares, Fondo, Reparaciones y Costas). Sentencia de 2 de julio de 2004. Serie C No. 107. Disponible en:http://www.corteidh.or.cr/docs/casos/articulos/seriec_107_esp.pdf

- Corte IDH. Caso IvcherBronstein Vs. Perú. (Fondo, Reparaciones y Costas). Sentencia de 6 de febrero de 2001. Serie C No. 74. Disponible en: http://www.corteidh.or.cr/docs/casos/articulos/Seriec_74_esp.pdf

- Corte IDH. Caso Kimel Vs. Argentina. (Fondo, Reparaciones y Costas). Sentencia de 2 de

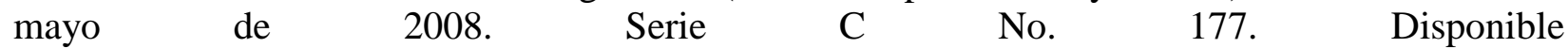
en:http://www.corteidh.or.cr/docs/casos/articulos/seriec_177_esp.pdf

- Corte IDH. Caso Palamara Iribarne Vs. Chile. (Fondo, Reparaciones y Costas). Sentencia de 22 de noviembre de 2005. Serie C No. 135.Disponible en:http://www.corteidh.or.cr/docs/casos/articulos/seriec_135_esp.pdf 
- Corte IDH. Caso Ricardo Canese Vs. Paraguay. (Fondo, Reparaciones y Costas). Sentencia de 31 de agosto de 2004. Serie C No. 111. Disponible en: http://www.corteidh.or.cr/docs/casos/articulos/seriec_111_esp.pdf

- Corte IDH. Caso Usón Ramírez Vs. Venezuela. (Excepción Preliminar, Fondo, Reparaciones y Costas). Sentencia de 20 de noviembre de 2009. Serie C No. 207. Disponible en:http://www.corteidh.or.cr/docs/casos/articulos/seriec_207_esp.pdf

- Corte IDH. Caso Ximenes Lopes Vs. Brasil. Sentencia de 4 de julio de 2006. Serie C No. 149. Disponible en: http://www.corteidh.or.cr/docs/casos/articulos/Seriec_149_esp.pdf

- Corte IDH. Caso Yatama Vs. Nicaragua. (Excepciones Preliminares, Fondo, Reparaciones y Costas). Sentencia de 23 de junio de 2005. Serie C No. 127. Disponible en: http://www.corteidh.or.cr/docs/casos/articulos/seriec_127_esp.pdf

- Corte IDH. Condición jurídica y derechos humanos del niño. Opinión Consultiva OC-17/02 de 28 de agosto de 2002. Serie A No. 17. Disponible en: http://www.corteidh.or.cr/docs/opiniones/seriea_17_esp.pdf.

- Corte IDH. La colegiación obligatoria de periodistas (Arts. 13 y 29 Convención Americana sobre Derechos Humanos). Opinión Consultiva OC-5/85 de 13 de noviembre de 1985. Serie A No. 5. Disponible en: http://www.corteidh.or.cr/docs/opiniones/seriea_05_esp.pdf

- Pacto Internacional de Derechos Civiles y Políticos. Resolución 2200 A (XXI), de 16 de diciembre de $1966 . \quad$ Disponible en: https://www.ohchr.org/SP/ProfessionalInterest/Pages/CCPR.aspx

- Protocolo adicional a la Convención Americana Sobre Derechos Humanos en materia de derechos económicos, sociales y culturales "Protocolo De San Salvador". 17 de noviembre de 1988. San Salvador, El Salvador. Disponible en:https://www.oas.org/juridico/spanish/tratados/a52.html 